NBER WORKING PAPER SERIES

\title{
OPTIMAL MONETARY POLICY IN A LIQUIDITY TRAP
}

\author{
Gauti B. Eggertsson \\ Michael Woodford \\ Working Paper 9968 \\ http://www.nber.org/papers/w9968 \\ NATIONAL BUREAU OF ECONOMIC RESEARCH \\ 1050 Massachusetts Avenue \\ Cambridge, MA 02138 \\ September 2003
}

Prepared for the International Workshop on Overcoming Deflation and Revitalizing the Japanese Economy, Economic and Social Research Institute, Tokyo, September 18, 2003. Parts of this paper have previously appeared in Eggertsson andWoodford (2003). We would like to thank Tamim Bayoumi, Ben Bernanke, Robin Brooks, Michael Dotsey, Martin Feldstein, Benjamin Friedman, Stefan Gerlach, Mark Gertler, Marvin Goodfriend, Kenneth Kuttner, Maurice Obstfeld, Athanasios Orphanides, Kenneth Rogoff, David Small, Lars Svensson, Harald Uhlig, Tsutomu Watanabe, and Alex Wolman for helpful comments, and the National Science Foundation for research support through a grant to the NBER. The views expressed in this paper are those of the authors and do not necessarily represent those of the IMF or IMF policy, nor are they necessarily those of the National Bureau of Economic Research.

(C)2003 by Gauti B. Eggertsson and Michael Woodford. All rights reserved. Short sections of text, not to exceed two paragraphs, may be quoted without explicit permission provided that full credit, including (C) notice, is given to the source. 
Optimal Monetary Policy in a Liquidity Trap

Gauti B. Eggertsson and Michael Woodford

NBER Working Paper No. 9968

September 2003

JEL No. E52

\title{
ABSTRACT
}

We consider the consequences for monetary policy of the zero floor for nominal interest rates. The zero bound can be a significant constraint on the ability of a central bank to combat deflation. We show, in the context of an intertemporal equilibrium model, that open-market operations, even of "unconventional" types, are ineffective if they do not change expectations about the future conduct of policy; in this sense, a "liquidity trap" is possible. Nonetheless, a credible commitment to the right sort of history-dependent policy can largely mitigate the distortions created by the zero bound. In our model, optimal policy involves a commitment to adjust interest rates so as to achieve a timevarying price-level target, when this is consistent with the zero bound. We also discuss ways in which other central-bank actions, while irrelevant apart from their effects on expectations, may help to make credible a central bank's commitment to its target, and consider implications for the policy options currently available for overcoming deflation in Japan.

\author{
Gauti B. Eggertsson \\ International Monetary Fund \\ $70019^{\text {th }}$ Street, NW \\ Washington, DC 20431 \\ geggertsson@imf.org \\ Michael Woodford \\ Department of Economics \\ Princeton University \\ Princeton, NJ 08544 \\ and NBER \\ woodford@princeton.edu
}


The consequences for the proper conduct of monetary policy of the existence of a lower bound of zero for overnight nominal interest rates has recently become a topic of lively interest. The relevance of this bound is nowhere more apparent than in the case of Japan, where the call rate (the overnight cash rate that is analogous to the federal funds rate in the U.S.) has been essentially at zero for most of the time since February 1999, when the policy board of the Bank of Japan decided to make it "as low as possible". (As shown in Figure 1, the call rate has actually been at or below 50 basis points since October 1995, so that little room for further reductions in short-term nominal interest rates has existed since that time.) At the same time, growth has remained anemic in Japan over this period, and prices have continued to fall, suggesting to many observers a need for further monetary stimulus. Yet the usual remedy - lower short-term nominal interest rates - is plainly unavailable.

This has led to interest in policies that might bring about further monetary stimulus, even taking as given the BOJ's "zero interest rate policy" (ZIRP). Since March 2001, the BOJ has supplemented the ZIRP with a policy of "quantitative easing," in which the supply of reserves to the banking system is increased beyond the level required in order to keep the call rate at zero. ${ }^{1}$ But even quite vigorous expansion of the monetary base (which, as shown in the figure, is now more than twice as large, relative to GDP, as in the early 1990s) has not as of yet been able to halt the deflation. This suggests that Japan is currently experiencing a "liquidity trap" of the kind hypothesized by Keynes (1936), though the practical possibility of such a situation continued for decades to be debated. ${ }^{2}$ The result is that a problem that was long treated as a mere theoretical curiosity - the question of what, if anything, monetary policy could do to halt deflation under such circumstances - now appears to be one of urgent practical importance.

\footnotetext{
${ }^{1}$ See Kimura et al. (2002) for discussion of this policy, as well as an expression of doubts about its effectiveness.

${ }^{2}$ Hetzel (2003) argues that there is no liquidity trap in Japan, on the ground that the public's holdings of M2 plus CDs remains only a little higher than an estimated demand function estimated using earlier data would have predicted; "there is no mushrooming demand indicative of a liquidity trap" (p. 32). But one should not expect to see "mushrooming demand" for money holdings on the part of the public, if the BOJ has no way of forcing the creation of additional M2. The monetary base is substantially higher now than a demand function estimated on data prior to 2001 would have predicted (see, e.g., Kimura et al., 2002), and this is what the BOJ policy of "quantitative easing" requires the private sector to hold more of.
} 
The fact that the federal funds rate has now been reduced to only one percent in the U.S., while signs of recovery remain exceedingly fragile, has led many to wonder if the U.S. could not also soon find itself in a situation where interest-rate policy would no longer be available as a tool for macroeconomic stabilization. In the U.S. debate as well, there has been considerable discussion of whether open-market operations should not still be effective in increasing nominal aggregate demand even when the zero bound on interest rates is reached. Some have suggested that while open-market purchases of short-term Treasury bills should be ineffective under such a circumstance - on the ground that short-term Treasury paper and base money become nearly perfect substitutes in the portfolios of private traders once the federal funds rate falls to zero - open-market purchases of other kinds of assets (longermaturity Treasury bonds, or even real assets), that do not promise the same state-contingent returns as money, should still stimulate aggregate demand. ${ }^{3}$ While Chairman Greenspan's congressional testimony in July 2003 has indicated that the Fed is unlikely to resort to such "unconventional" open-market operations in the near term, the question of the degree to which such operations would be more effective is an important one, especially for countries like Japan, where the risk of deflation is no longer a matter of conjecture. ${ }^{4}$

The question of how policy should be conducted when the zero bound is reached raises fundamental issues for the theory of monetary policy. Is a "liquidity trap" really possible, in the sense of a situation in which there is really nothing that the central bank can do to increase aggregate nominal spending or prevent continuing deflation? If monetary policy can instead be effective even when the zero bound has been reached, does its effectiveness depend on a resort to "unconventional" forms of open-market operations? And to what extent is the optimal conduct of policy different than it would be if the zero bound were never a binding constraint?

Here we seek to shed light on these issues by considering the consequences of the zero lower

\footnotetext{
${ }^{3}$ See, e.g., Bernanke (2002), Cecchetti (2003), and Clouse et al. (2003).

${ }^{4}$ For example, Meltzer (2003) argues that "quantitative easing" was ineffective in Japan until the BOJ began purchasing longer-term JGBs, but attributes the recent increase in Japanese real growth to a policy of money-financed bond purchases.
} 

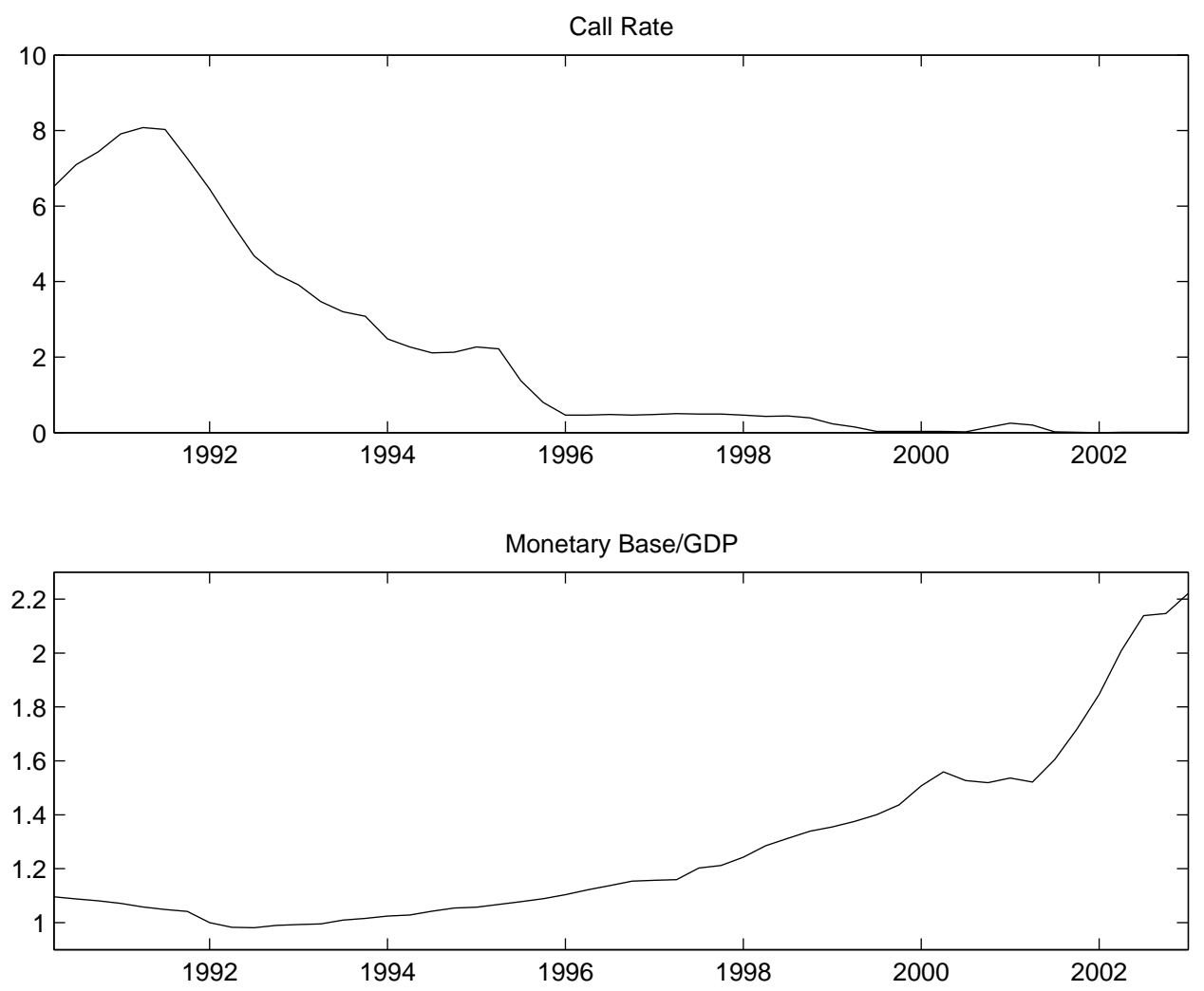

Figure 1: Evolution of the call rate on uncollateralized overnight loans in Japan, and the Japanese monetary base relative to GDP $[1992=1.0]$.

bound on nominal interest rates for the optimal conduct of monetary policy, in the context of an explicit intertemporal equilibrium model of the monetary transmission mechanism. While our model remains an extremely simple one, we believe that it can help to clarify basic issues. We are able to consider the extent to which the zero bound represents a genuine constraint on attainable equilibrium paths for inflation and real activity, and to consider the extent to which open-market purchases of various kinds of assets by the central bank can mitigate that constraint. We are also able to show how the character of optimal monetary policy changes as a result of the existence of the zero bound, relative to the policy rules that would be judged optimal in the absence of such a bound, or in the case of real disturbances small enough for the bound never to matter under an optimal policy.

To preview our results, we find that the zero bound does represent an important con- 
straint on what monetary stabilization policy can achieve, at least when certain kinds of real disturbances are encountered in an environment of low inflation. We argue that the possibility of expansion of the monetary base through central-bank purchases of a variety of types of assets does little if anything to expand the set of feasible equilibrium paths for inflation and real activity that are consistent with equilibrium under some (fully credible) policy commitment. Hence the relevant tradeoffs can correctly be studied by simply considering what can be achieved by alternative anticipated state-contingent paths of the short-term nominal interest rate, taking into account the constraint that this quantity must be non-negative at all times. When we consider such a problem, we find that the zero interest-rate bound can indeed be temporarily binding, and in such a case it inevitably results in lower welfare than could be achieved in the absence of such a constraint. ${ }^{5}$

Nonetheless, we argue that the extent to which this constraint restricts possible stabilization outcomes under sound policy is much more modest than is presumed by the deflation pessimists who have been widely quoted in the U.S. and European financial press in recent months. Even though the set of feasible equilibrium outcomes corresponds to those that can be achieved through alternative interest-rate policies, monetary policy is far from powerless to mitigate the contractionary effects of the kind of disturbances that would make the zero bound a binding constraint. The key to dealing with this sort of situation in the least damaging way is to create the right kind of expectations regarding the way in which monetary policy will be used subsequently, at a time when the central bank again has room to maneuver. We use our intertemporal equilibrium model to characterize the kind of expectations

\footnotetext{
${ }^{5}$ We do not here explore the possibility of relaxing the constraint by taxing money balances, as originally proposed by Gesell (1929) and Keynes (1936), and more recently by Buiter and Panigirtzoglou (1999) and Goodfriend (2000). While this represents a solution to the problem in theory, there are substantial practical difficulties with such a proposal, not least the political opposition that such an institutional change would be likely to generate. Our consideration of the optimal policy problem also abstracts from the availability of fiscal instruments such as the time-varying tax policy recommended by Feldstein (2002). We agree with Feldstein that there is a particularly good case for state-contingent fiscal policy as a way of dealing with a liquidity trap, even if fiscal policy is not a very useful tool for stabilization policy more generally. Nonetheless, we consider here only the problem of the proper conduct of monetary policy, taking as given the structure of tax distortions. As long as one does not think that state-contingent fiscal policy can (or will) be used to eliminate even temporary declines in the natural rate of interest below zero, the problem for monetary policy that we consider here remains relevant.
} 
regarding future policy that it would be desirable to create, and discuss a form of price-level targeting rule that - if credibly committed to by the central bank — should bring about the constrained-optimal equilibrium. We also discuss, more informally, ways in which other types of policy actions could help to increase the credibility of the central bank's announced commitment to this kind of future policy.

Our analysis will be recognized as a development of several key themes of Paul Krugman's (1998) treatment of the same topic. Like Krugman, we give particular emphasis to the role of expectations regarding future policy in determining the severity of the distortions that result from hitting the zero bound. Our primary contribution, relative to Krugman's earlier treatment, will be the presentation of a more fully dynamic analysis. For example, our assumption of staggered pricing, rather than the simple hypothesis of prices that are fixed for one period as in the analysis of Krugman, allows for richer (and at least somewhat more realistic) dynamic responses to disturbances. In our model, unlike Krugman's, a real disturbance that lowers the natural rate of interest can cause output to remain below potential for years (as shown in Figure 2 below), rather than only for a single "period", even when the average frequency of price adjustments is more than once per year. These richer dynamics are also important for a realistic discussion of the kind of policy commitment that can help to reduce economic contraction during a "liquidity trap". In our model, a commitment to create subsequent inflation involves a commitment to keep interest rates low for a time in the future, whereas in Krugman's model, a commitment to a higher future price level does not involve any reduction in future nominal interest rates. We are also better able to discuss questions such as how the creation of inflationary expectations during the period that the zero bound is binding can be reconciled with maintaining the credibility of the central bank's commitment to long-run price stability.

Our dynamic analysis also allows us to further clarify the several ways in which the management of private-sector expectations by the central bank can be expected to mitigate the effects of the zero bound. Krugman emphasizes the fact that increased expectations of inflation can lower the real interest rate implied by a zero nominal interest rate. This 
might suggest, however, that the central bank can affect the economy only insofar as it affects expectations regarding a variable that it cannot influence except quite indirectly; and it might also suggest that the only expectations that should matter are those regarding inflation over the relatively short horizon corresponding to the short-term nominal interest rate that has fallen to zero. Such interpretations easily lead to skepticism about the practical effectiveness of the expectational channel, especially if inflation is regarded as being relatively "sticky" in the short run. Our model is instead one in which expectations affect aggregate demand through several channels. First of all, it is not merely short-term real interest rates that matter for current aggregate demand; our model of intertemporal substitution in spending implies that the entire expected future path of short real rates should matter, or alternatively that very long real rates should matter. ${ }^{6}$ This means that the creation of inflation expectations, even with regard to inflation that should occur only more than a year in the future, should also be highly relevant to aggregate demand, as long as it is not accompanied by correspondingly higher expected future nominal interest rates. Furthermore, the expected future path of nominal interest rates matters, and not just their current level, so that a commitment to keep nominal interest rates low for a longer period of time should stimulate aggregate demand, even when current rates cannot be further lowered, and even under the hypothesis that inflation expectations would remain unaffected. Since the central bank can clearly control the future path of short-term nominal interest rates if it has the will to do so, any failure of such a commitment to be credible will not be due to skepticism about whether the central bank is able to follow through on its commitment.

The richer dynamics of our model are also important for the analysis of optimal policy. Krugman mainly addresses the question whether monetary policy is completely impotent when the zero bound binds, and argues for the possibility of increasing real activity in the

\footnotetext{
${ }^{6}$ In the simple model presented here, this occurs solely as a result of intertemporal substitution in private expenditure. But there are a number of reasons to expect long rates, rather than short rates, to be the critical determinant of aggregate demand. For example, in an open-economy model, the real exchange rate becomes an important determinant of aggregate demand. But the real exchange rate should be closely linked to a very long domestic real rate of return (or alternatively, to the expected future path of short rates) as a result of interest-rate parity, together with an anchor for the expected long-term real exchange rate (coming, for example, from long-run purchasing-power parity).
} 
"liquidity trap" by creating expectations of inflation. This conclusion in itself, however (with which we agree), does not answer the question whether, or to what extent, it should actually be desirable to create such expectations, given the well-founded reasons that the central bank should have to not prefer inflation at a later time. Nor is Krugman's model well-suited to address such a question, insofar as it omits any reason for even an extremely high degree of subsequent inflation to be harmful. Our model with staggered pricing, instead, implies that inflation (whether anticipated or not) creates distortions, and justifies an objective function for stabilization policy that trades off inflation stabilization and output-gap stabilization in terms that are often assumed to represent actual central-bank concerns. We characterize optimal policy in such a setting, and show that it does indeed involve a commitment to history-dependent policy of a sort that should result in higher inflation expectations in response to a binding zero bound. We can also show to what extent it should be optimal to create such expectations, assuming that this is possible. We find, for example, that it is not optimal to commit to so much future inflation that the zero bound ceases to bind, even though this is one possible type of equilibrium; this is why the zero bound does remain a relevant constraint, even under an optimal policy commitment.

\section{Is "Quantitative Easing" a Separate Policy Instru- ment?}

A first question that we wish to consider is whether expansion of the monetary base represents a policy instrument that should be effective in preventing deflation and associated output declines, even after overnight interest rates have fallen to zero. Specifically, we wish to consider whether a policy of "quantitative easing" like that currently followed by the Bank of Japan - conceived of as an additional aspect of policy, alongside the "zero interest-rate policy" that continues to be maintained - should help to prevent further deflation. We also wish to consider the extent to which it matters which sorts of assets may be acquired by the central bank - that is, whether "unconventional" open-market operations should be expected to be more effective than simple purchases of short-term Treasury bills, as has 
often been suggested in recent discussion of U.S. policy options.

Here we consider this question in the context of an explicit intertemporal equilibrium model, in which we model both the demand for money and the role of financial assets (including the monetary base) in private-sector budget constraints. The model that we use for this purpose is more detailed in several senses than the one used in subsequent sections to characterize optimal policy, in order to make it clear that we have not excluded a role for "quantitative easing" simply by failing to model the role of money in the economy. The model is discussed in more detail in Woodford (2003, chapter 4), where the consequences of various interest-rate rules and money-growth rules are considered under the assumption that disturbances are not large enough for the zero bound to bind.

Our key result is an irrelevance proposition for open market operations in a variety of types of assets that might be acquired by the central bank, under the assumption that the open market operations do not change the expected future conduct of monetary or fiscal policy (in senses that we make precise below). It is perhaps worth stating from the start that our intention in stating such a result is not to vindicate the view that a central bank is powerless to halt a deflationary slump, and hence to absolve the Bank of Japan, for example, from any responsibility for the continuing stagnation in that country. While our proposition establishes that there is a sense in which a "liquidity trap" is possible, this does not mean that the central bank is powerless under the circumstances that we describe. Rather, the point of our result is to show that the key to effective central-bank action to combat a deflationary slump is the management of expectations. Open-market operations should be largely ineffective to the extent that they fail to change expectations regarding future policy; the conclusion that we draw is not that such actions are futile, but rather that the central bank's actions should be chosen with a view to signalling the nature of its policy commitments, and not in order to create some sort of "direct" effects. 


\subsection{A Neutrality Proposition for Open-Market Operations}

Our model abstracts from endogenous variations in the capital stock, and assumes perfectly flexible wages (or some other mechanism for efficient labor contracting), but assumes monopolistic competition in goods markets, and sticky prices that are adjusted at random intervals in the way assumed by Calvo (1983), so that deflation has real effects. We assume a model in which the representative household seeks to maximize a utility function of the form

$$
E_{t} \sum_{T=t}^{\infty} \beta^{T-t}\left[u\left(C_{t}, M_{t} / P_{t} ; \xi_{t}\right)-\int_{0}^{1} v\left(H_{t}(j) ; \xi_{t}\right) d j\right],
$$

where $C_{t}$ is a Dixit-Stiglitz aggregate of consumption of each of a continuum of differentiated goods,

$$
C_{t} \equiv\left[\int_{0}^{1} c_{t}(i)^{\frac{\theta}{\theta-1}} d i\right]^{\frac{\theta-1}{\theta}}
$$

with an elasticity of substitution equal to $\theta>1, M_{t}$ measures end-of-period household money balances, ${ }^{7} P_{t}$ is the Dixit-Stiglitz price index,

$$
P_{t} \equiv\left[\int_{0}^{1} p_{t}(i)^{1-\theta} d i\right]^{\frac{1}{1-\theta}}
$$

and $H_{t}(j)$ is the quantity supplied of labor of type $j$. (Each industry $j$ employs an industryspecific type of labor, with its own wage $w_{t}(j)$.) Real balances are included in the utility function, following Sidrauski (1967) and Brock (1974, 1975), as a proxy for the services that money balances provide in facilitating transactions. ${ }^{8}$

For each value of the disturbances $\xi_{t}, u\left(\cdot, \cdot ; \xi_{t}\right)$ is concave function, increasing in the first argument, and increasing in the second for all levels of real balances up to a satiation level $\bar{m}\left(C_{t} ; \xi_{t}\right)$. The existence of a satiation level is necessary in order for it to be possible for the zero interest-rate bound ever to be reached; we regard Japan's experience over the past

\footnotetext{
${ }^{7}$ We shall not introduce fractional-reserve banking into our model. Technically, $M_{t}$ refers to the monetary base, and we represent households as obtaining liquidity services from holding this base, either directly or through intermediaries (not modelled).

${ }^{8}$ We use this approach to modelling the transactions demand for money because of its familiarity. As shown in Woodford (2003, appendix section A.16), a cash-in-advance model leads to equilibrium conditions of essentially the same general form, and the neutrality result that we present below would hold in essentially identical form were we to model the transactions demand for money after the fashion of Lucas and Stokey (1987).
} 
several years as having settled the theoretical debate over whether such a level of real balances exists. Unlike many papers in the literature, we do not assume additive separability of the function $u$ between the first two arguments; this (realistic) complication allows a further channel through which money can affect aggregate demand, namely an effect of real money balances on the current marginal utility of consumption. Similarly, for each value of $\xi_{t}, v\left(\cdot ; \xi_{t}\right)$ is an increasing convex function. The vector of exogenous disturbances $\xi_{t}$ may contain several elements, so that no assumption is made about correlation of the exogenous shifts in the functions $u$ and $v$.

For simplicity we shall assume complete financial markets and no limits on borrowing against future income. As a consequence, a household faces an intertemporal budget constraint of the form

$$
E_{t} \sum_{T=t}^{\infty} Q_{t, T}\left[P_{T} C_{T}+\delta_{T} M_{T}\right] \leq W_{t}+E_{t} \sum_{T=t}^{\infty} Q_{t, T}\left[\int_{0}^{1} \Pi_{T}(i) d i+\int_{0}^{1} w_{T}(j) H_{T}(j) d j-T_{T}^{h}\right]
$$

looking forward from any period $t$. Here $Q_{t, T}$ is the stochastic discount factor by which the financial markets value random nominal income at date $T$ in monetary units at date $t, \delta_{t}$ is the opportunity cost of holding money (equal to $i_{t} /\left(1+i_{t}\right)$, where $i_{t}$ is the riskless nominal interest rate on one-period obligations purchased in period $t$, in the case that no interest is paid on the monetary base), $W_{t}$ is the nominal value of the household's financial wealth (including money holdings) at the beginning of period $t, \Pi_{t}(i)$ represents the nominal profits (revenues in excess of the wage bill) in period $t$ of the supplier of good $i, w_{t}(j)$ is the nominal wage earned by labor of type $j$ in period $t$, and $T_{t}^{h}$ represents the net nominal tax liabilities of each household in period $t$.

Optimizing household behavior then implies the following necessary conditions for a rational-expectations equilibrium. Optimal timing of household expenditure requires that aggregate demand $Y_{t}$ for the composite good $^{9}$ satisfy an Euler equation of the form

$$
u_{c}\left(Y_{t}, M_{t} / P_{t} ; \xi_{t}\right)=\beta E_{t}\left[u_{c}\left(Y_{t+1}, M_{t+1} / P_{t+1} ; \xi_{t+1}\right)\left(1+i_{t}\right) \frac{P_{t}}{P_{t+1}}\right]
$$

\footnotetext{
${ }^{9}$ For simplicity, we here abstract from government purchases of goods. Our equilibrium conditions directly extend to the case of exogenous government purchases, as shown in Woodford (2003, chap. 4).
} 
where $i_{t}$ is the riskless nominal interest rate on one-period obligations purchased in period $t$.

Optimal substitution between real money balances and expenditure leads to a static first-order condition of the form

$$
\frac{u_{m}\left(Y_{t}, M_{t} / P_{t} ; \xi_{t}\right)}{u_{c}\left(Y_{t}, M_{t} / P_{t} ; \xi_{t}\right)}=\frac{i_{t}}{1+i_{t}},
$$

under the assumption that zero interest is paid on the monetary base, and that preferences are such that we can exclude the possibility of a corner solution with zero money balances. If both consumption and liquidity services are normal goods, this equilibrium condition can be solved uniquely for the level of real balances $L\left(Y_{t}, i_{t} ; \xi_{t}\right)$ that satisfy it in the case of any positive nominal interest rate. ${ }^{10}$ The equilibrium relation can then equivalently be written as a pair of inequalities

$$
\begin{gathered}
\frac{M_{t}}{P_{t}} \geq L\left(Y_{t}, i_{t} ; \xi_{t}\right), \\
i_{t} \geq 0,
\end{gathered}
$$

together with the "complementary slackness" condition that at least one must hold with equality at any time. (Here we define $L(Y, 0 ; \xi)=\bar{m}(Y ; \xi)$, the minimum level of real balances for which $u_{m}=0$, so that the function $L$ is continuous at $i=0$.)

Household optimization similarly requires that the paths of aggregate real expenditure and the price index satisfy the bounds

$$
\begin{gathered}
\sum_{T=t}^{\infty} \beta^{T} E_{t}\left[u_{c}\left(Y_{T}, M_{T} / P_{T} ; \xi_{T}\right) Y_{T}+u_{m}\left(Y_{T}, M_{T} / P_{T} ; \xi_{T}\right)\left(M_{T} / P_{T}\right)\right]<\infty, \\
\lim _{T \rightarrow \infty} \beta^{T} E_{t}\left[u_{c}\left(Y_{T}, M_{T} / P_{T} ; \xi_{T}\right) D_{T} / P_{T}\right]=0
\end{gathered}
$$

looking forward from any period $t$, where $D_{t}$ measures the total nominal value of government liabilities (monetary base plus government debt) at the end of period $t$. under the monetary-fiscal policy regime. (Condition (1.5) is required for the existence of a well-defined intertemporal budget constraint, under the assumption that there are no limitations on households' ability to borrow against future income, while the transversality condition (1.6)

\footnotetext{
${ }^{10}$ In the case that $i_{t}=0, L\left(Y_{t}, 0 ; \xi_{t}\right)$ is defined as the minimum level of real balances that would satisfy the first-order condition, so that the function $L$ is continuous.
} 
must hold if the household exhausts its intertemporal budget constraint.) Conditions (1.2) - (1.6) also suffice to imply that the representative household chooses optimal consumption and portfolio plans (including its planned holdings of money balances) given its income expectations and the prices (including financial asset prices) that it faces, while making choices that are consistent with financial market clearing.

Each differentiated good $i$ is supplied by a single monopolistically competitive producer. There are assumed to be many goods in each of an infinite number of "industries"; the goods in each industry $j$ are produced using a type of labor that is specific to that industry, and also change their prices at the same time. Each good is produced in accordance with a common production function

$$
y_{t}(i)=A_{t} f\left(h_{t}(i)\right)
$$

where $A_{t}$ is an exogenous productivity factor common to all industries, and $h_{t}(i)$ is the industry-specific labor hired by firm $i$. The representative household supplies all types of labor as well as consuming all types of goods. ${ }^{11}$

The supplier of good $i$ sets a price for that good at which it supplies demand each period, hiring the labor inputs necessary to meet any demand that may be realized. Given the allocation of demand across goods by of households in response to firm pricing decisions, on the one hand, and the terms on which optimizing households are willing to supply each type of labor on the other, we can show that the nominal profits (sales revenues in excess of labor costs) in period $t$ of the supplier of good $i$ are given by a function

$$
\begin{aligned}
\Pi\left(p_{t}(i), p_{t}^{j}, P_{t} ; Y_{t}, M_{t} / P_{t}, \tilde{\xi}_{t}\right) \equiv & p_{t}(i) Y_{t}\left(p_{t}(i) / P_{t}\right)^{-\theta} \\
& -\frac{v_{h}\left(f^{-1}\left(Y_{t}\left(p_{t}^{j} / P_{t}\right)^{-\theta} / A_{t}\right) ; \xi_{t}\right)}{u_{c}\left(Y_{t}, M_{t} / P_{t} ; \xi_{t}\right)} P_{t} f^{-1}\left(Y_{t}\left(p_{t}(i) / P_{t}\right)^{-\theta} / A_{t}\right),
\end{aligned}
$$

where $p_{t}^{j}$ is the common price charged by the other firms in industry $j .{ }^{12}$ (We introduce the notation $\tilde{\xi}_{t}$ for the complete vector of exogenous disturbances, including variations in

\footnotetext{
${ }^{11}$ We might alternatively assume specialization across households in the type of labor supplied; in the presence of perfect sharing of labor income risk across households, household decisions regarding consumption and labor supply would all be as assumed here.

${ }^{12}$ In equilibrium, all firms in an industry charge the same price at any time. But we must define profits for an individual supplier $i$ in the case of contemplated deviations from the equilibrium price.
} 
technology as well as preferences.) If prices were fully flexible, $p_{t}(i)$ would be chosen each period to maximize this function.

Instead we suppose that prices remain fixed in monetary terms for a random period of time. Following Calvo (1983), we suppose that each industry has an equal probability of reconsidering its prices each period, and let $0<\alpha<1$ be the fraction of industries with prices that remain unchanged each period. In any industry that revises its prices in period $t$, the new price $p_{t}^{*}$ will be the same. This price is implicitly defined by the first-order condition

$$
E_{t}\left\{\sum_{T=t}^{\infty} \alpha^{T-t} Q_{t, T} \Pi_{1}\left(p_{t}^{*}, p_{t}^{*}, P_{T} ; Y_{T}, M_{T} / P_{T}, \tilde{\xi}_{T}\right)\right\}=0 .
$$

We note furthermore that the stochastic discount factor used to price future profit streams will be given by

$$
Q_{t, T}=\beta^{T-t} \frac{u_{c}\left(C_{T}, M_{T} / P_{T} ; \xi_{T}\right)}{u_{c}\left(C_{t}, M_{t} / P_{t} ; \xi_{t}\right)} .
$$

Finally, the definition (1.1) implies a law of motion for the aggregate price index of the form

$$
P_{t}=\left[(1-\alpha) p_{t}^{* 1-\theta}+\alpha P_{t-1}^{1-\theta}\right]^{\frac{1}{1-\theta}} .
$$

Equations (1.7) and (1.9) jointly determine the evolution of prices given demand conditions, and represent the aggregate-supply block of our model.

It remains to specify the monetary and fiscal policies of the government. ${ }^{13}$ In order to address the question whether "quantitative easing" represents an additional tool of policy, we shall suppose that the central bank's operating target for the short-term nominal interest rate is determined by a feedback rule in the spirit of the Taylor rule (Taylor, 1993),

$$
i_{t}=\phi\left(P_{t} / P_{t-1}, Y_{t} ; \tilde{\xi}_{t}\right)
$$

\footnotetext{
${ }^{13}$ It is important to note that the specification of monetary and fiscal policy in the particular way that we propose here is not intended to suggest that either monetary or fiscal policy must be expected to be conducted according to rules of the sort assumed here. Indeed, in later sections of this paper, we recommend policy commitments on the part of both monetary and fiscal authorities that do not conform to the assumptions made in this section. The point is to define what we mean by the qualification that open-market operations are irrelevant if they do not change expected future monetary or fiscal policy. In order to make sense of such a statement, we must define what it would mean for these policies to be specified in a way that prevents them from being affected by past open-market operations. The specific classes of policy rules discussed here show that our concept of "unchanged policy" is not only logically possible, but that it could correspond to a policy commitment of a fairly familiar sort, one that would represent a commitment to "sound policy" in the views of some.
} 
where now $\tilde{\xi}_{t}$ may also include exogenous disturbances in addition to the ones listed above, to which the central bank happens to respond. We shall assume that the function $\phi$ is nonnegative for all values of its arguments (otherwise the policy would not be feasible, given the zero lower bound), but that there are conditions under which the rule prescribes a zero interest-rate policy. Such a rule implies that the central bank supplies the quantity of base money that happens to be demanded at the interest rate given by this formula; hence (1.10) implies a path for the monetary base, in the case that the value of $\phi$ is positive. However, under those conditions in which the value of $\phi$ is zero, the policy commitment (1.10) implies only a lower bound on the monetary base that must be supplied. In these circumstances, we may ask whether it matters whether a greater or smaller quantity of base money is supplied.

We shall suppose that the central bank's policy in this regard is specified by a base-supply rule of the form

$$
M_{t}=P_{t} L\left(Y_{t}, \phi\left(P_{t} / P_{t-1}, Y_{t} ; \tilde{\xi}_{t}\right) ; \xi_{t}\right) \psi\left(P_{t} / P_{t-1}, Y_{t} ; \tilde{\xi}_{t}\right)
$$

where the multiplicative factor $\psi$ satisfies

(i) $\psi\left(P_{t} / P_{t-1}, Y_{t} ; \tilde{\xi}_{t}\right) \geq 1$

(ii) $\psi\left(P_{t} / P_{t-1}, Y_{t} ; \tilde{\xi}_{t}\right)=1$ if $\phi\left(P_{t} / P_{t-1}, Y_{t} ; \tilde{\xi}_{t}\right)>0$

for all values of its arguments. (Condition (ii) implies that $\psi=1$ whenever $i_{t}>0$.) Note that a base-supply rule of this form is consistent with both the interest-rate operating target specified in (1.10) and the equilibrium relations (1.3) - (1.4). The use of "quantitative easing" as a policy tool can then be represented by a choice of a function $\psi$ that is greater than 1 under some circumstances.

It remains to specify which sort of assets should be acquired (or disposed of) by the central bank when it varies the size of the monetary base. We shall suppose that the asset side of the central-bank balance sheet may include any of $k$ different types of securities, distinguished by their state-contingent returns. At the end of period $t$, the vector of nominal values of central-bank holdings of the various securities is given by $M_{t} \omega_{t}^{m}$, where $\omega_{t}^{m}$ is a vector of central-bank portfolio shares. These shares are in turn determined by a policy rule 
of the form

$$
\omega_{t}^{m}=\omega^{m}\left(P_{t} / P_{t-1}, Y_{t} ; \tilde{\xi}_{t}\right),
$$

where the vector-valued function $\omega^{m}(\cdot)$ has the property that its components sum to 1 for all possible values of its arguments. The fact that $\omega^{m}(\cdot)$ depends on the same arguments as $\phi(\cdot)$ means that we allow for the possibility that the central bank changes its policy when the zero bound is binding (for example, buying assets that it would not hold at any other time); the fact that it depends on the same arguments as $\psi(\cdot)$ allows us to specify changes in the composition of the central-bank portfolio as a function of the particular kinds of purchases associated with "quantitative easing."

The payoffs on these securities in each state of the world are specified by exogenously given (state-contingent) vectors $a_{t}$ and $b_{t}$ and matrix $F_{t}$. A vector of asset holdings $z_{t-1}$ at the end of period $t-1$ results in delivery to the owner of a quantity $a_{t}^{\prime} z_{t-1}$ of money, a quantity $b_{t}^{\prime} z_{t-1}$ of the consumption good, and a vector $F_{t} z_{t-1}$ of securities that may be traded in the period $t$ asset markets, each of which may depend on the state of the world in period $t$. This flexible specification allows us to treat a wide range of types of assets that may differ as to maturity, degree of indexation, and so on. ${ }^{14}$

The gross nominal return $R_{t}(j)$ on the $j$ th asset between periods $t-1$ and $t$ is then given by

$$
R_{t}(j)=\frac{a_{t}(j)+P_{t} b_{t}(j)+q_{t}^{\prime} F_{t}(\cdot, j)}{q_{t-1}(j)},
$$

where $q_{t}$ is the vector of nominal asset prices in (ex-dividend) period $t$ trading. The absence of arbitrage opportunities implies as usual that equilibrium asset prices must satisfy

$$
q_{t}^{\prime}=\sum_{T \geq t+1} E_{t} Q_{t, T}\left[a_{T}^{\prime}+P_{t} b_{T}^{\prime}\right] \prod_{s=t+1}^{T-1} F_{s},
$$

where the stochastic discount factor is again given by (1.8). Under the assumption that no interest is paid on the monetary base, the nominal transfer by the central bank to the

\footnotetext{
${ }^{14}$ For example, security $j$ in period $t-1$ is a one-period riskless nominal bond if $b_{t}(j)$ and $F_{t}(\cdot, j)$ are zero in all states, while $a_{t}(j)>0$ is the same in all states. Security $j$ is instead a one-period real (or indexed) bond if $a_{t}(j)$ and $F_{t}(\cdot, j)$ are zero, while $b_{t}(j)>0$ is the same in all states. It is a two-period riskless nominal pure discount bond if instead $a_{t}(j)$ and $b_{t}(j)$ are zero, $F_{t}(i, j)=0$ for all $i \neq k, F_{t}(k, j)>0$ is the same in all states, and security $k$ in period $t$ is a one-period riskless nominal bond.
} 
Treasury each period is equal to

$$
T_{t}^{c b}=R_{t}^{\prime} \omega_{t-1}^{m} M_{t-1}-M_{t-1},
$$

where $R_{t}$ is the vector of returns defined by (1.13).

We specify fiscal policy in terms of a rule that determines the evolution of total government liabilities $D_{t}$, here defined to be inclusive of the monetary base, as well as a rule that specifies the composition of outstanding non-monetary liabilities (debt) among different types of securities that might be issued by the government. We shall suppose that the evolution of total government liabilities is in accordance with a rule of the form

$$
\frac{D_{t}}{P_{t}}=d\left(\frac{D_{t-1}}{P_{t-1}}, \frac{P_{t}}{P_{t-1}}, Y_{t} ; \tilde{\xi}_{t}\right),
$$

which specifies the acceptable level of real government liabilities as a function of the preexisting level of real liabilities and various aspects of current macroeconomic conditions. This notation allows for such possibilities as an exogenously specified state-contingent target for real government liabilities as a proportion of GDP, or for the government budget deficit (inclusive of interest on the public debt) as a share of GDP, among others.

The part of total liabilities that consists of base money is specified by the base rule (1.11). We suppose, however, that the rest may be allocated among any of a set of different types of securities that may be issued by the government; for convenience, we assume that this is a subset of the set of $k$ securities that may be purchased by the central bank. If $\omega_{j t}^{f}$ indicates the share of government debt (i.e., non-monetary liabilities) at the end of period $t$ that is of type $j$, then the flow government budget constraint takes the form

$$
D_{t}=R_{t}^{\prime} \omega_{t-1}^{f} B_{t-1}-T_{t}^{c b}-T_{t}^{h}
$$

where $B_{t} \equiv D_{t}-M_{t}$ is the total nominal value of end-of-period non-monetary liabilities, and $T_{t}^{h}$ is the nominal value of the primary budget surplus (taxes net of transfers, if we abstract from government purchases). This identity can then be inverted to obtain the net tax collections $T_{t}^{h}$ implied by a given rule (1.16) for aggregate public liabilities; this depends in general on the composition of the public debt as well as on total borrowing. 
Finally, we suppose that debt management policy (i.e., the determination of the composition of the government's non-monetary liabilities at each point in time) is specified by a function

$$
\omega_{t}^{f}=\omega^{f}\left(P_{t} / P_{t-1}, Y_{t} ; \tilde{\xi}_{t}\right)
$$

specifying the shares as a function of aggregate conditions, where the vector-valued function $\omega^{f}$ also has components that sum to 1 for all possible values of its arguments. Together, the two relations (1.16) and (1.17) complete our specification of fiscal policy, and close our model. ${ }^{15}$

We may now define a rational-expectations equilibrium as a collection of stochastic processes $\left\{p_{t}^{*}, P_{t}, Y_{t}, i_{t}, q_{t}, M_{t}, \omega_{t}^{m}, D_{t}, \omega_{t}^{f}\right\}$, with each endogenous variable specified as a function of the history of exogenous disturbances to that date, that satisfy each of conditions (1.2) (1.6) of the aggregate-demand block of the model, conditions (1.7) and (1.9) of the aggregatesupply block, the asset-pricing relations (1.14), conditions (1.10) - (1.12) specifying monetary policy, and conditions (1.16) - (1.17) specifying fiscal policy each period. We then obtain the following irrelevance result for the specification of certain aspects of policy.

Proposition. The set of paths for the variables $\left\{p_{t}^{*}, P_{t}, Y_{t}, i_{t}, q_{t}, D_{t}\right\}$ that are consistent with the existence of a rational-expectations equilibrium are independent of the specification of the functions $\psi$ in equation (1.11), $\omega^{m}$ in equation (1.12), and $\omega^{f}$ in equation (1.17).

The reason for this is fairly simple. The set of restrictions on the processes $\left\{p_{t}^{*}, P_{t}, Y_{t}, i_{t}, q_{t}, D_{t}\right\}$ implied by our model can be written in a form that does not involve the variables $\left\{M_{t}, \omega_{t}^{m}, \omega_{t}^{f}\right\}$, and hence that does not involve the functions $\psi, \omega^{m}$, or $\omega^{f}$.

To show this, let us first note that for all $m \geq \bar{m}(C ; \xi)$,

$$
u(C, m ; \xi)=u(C, \bar{m}(C ; \xi) ; \xi),
$$

\footnotetext{
${ }^{15}$ We might, of course, allow for other types of fiscal decisions from which we abstract here - government purchases, tax incentives, and so on — some of which may be quite relevant to dealing with a "liquidity trap." But our concern here is solely with the question of what can be achieved by monetary policy; we introduce a minimal specification of fiscal policy only for the sake of closing our general-equilibrium model, and in order to allow discussion of the fiscal implications of possible actions by the central bank.
} 
as additional money balances beyond the satiation level provide no further liquidity services. By differentiating this relation, we see further that $u_{c}(C, m ; \xi)$ does not depend on the exact value of $m$ either, as long as $m$ exceeds the satiation level. It follows that in our equilibrium relations, we can replace the expression $u_{c}\left(Y_{t}, M_{t} / P_{t} ; \xi_{t}\right)$ by

$$
\lambda\left(Y_{t}, P_{t} / P_{t-1} ; \xi_{t}\right) \equiv u_{c}\left(Y_{t}, L\left(Y_{t}, \phi\left(P_{t} / P_{t-1}, Y_{t} ; \xi_{t}\right) ; \xi_{t}\right) ; \xi_{t}\right)
$$

using the fact that (1.3) holds with equality at all levels of real balances at which $u_{c}$ depends on the level of real balances. Hence we can write $u_{c}$ as a function of variables other than $M_{t} / P_{t}$, without using the relation (1.11), and so in a way that is independent of the function $\psi$.

We can similarly replace the expression $u_{m}\left(Y_{t}, M_{t} / P_{t} ; \xi_{t}\right)\left(M_{t} / P_{t}\right)$ that appears in $(1.5)$ by

$$
\mu\left(Y_{t}, P_{t} / P_{t-1} ; \xi_{t}\right) \equiv u_{m}\left(Y_{t}, L\left(Y_{t}, \phi\left(P_{t} / P_{t-1}, Y_{t} ; \xi_{t}\right) ; \xi_{t}\right) ; \xi_{t}\right) L\left(Y_{t}, \phi\left(P_{t} / P_{t-1}, Y_{t} ; \xi_{t}\right) ; \xi_{t}\right)
$$

since $M_{t} / P_{t}$ must equal $L\left(Y_{t}, \phi\left(P_{t} / P_{t-1}, Y_{t} ; \xi_{t}\right) ; \xi_{t}\right)$ when real balances do not exceed the satiation level, while $u_{m}=0$ when they do. Finally, we can express nominal profits in period $t$ as a function

$$
\tilde{\Pi}\left(p_{t}(i), p_{t}^{j}, P_{t} ; Y_{t}, P_{t} / P_{t-1}, \tilde{\xi}_{t}\right)
$$

after substituting $\lambda\left(Y_{t}, P_{t} / P_{t-1} ; \xi_{t}\right)$ for the marginal utility of real income in the wage demand function that is used (see Woodford, 2003, chapter 3) in deriving the profit function $\Pi$. Using these substitutions, we can write each of the equilibrium relations (1.2), (1.5), (1.6), (1.7), and (1.14) in a way that no longer makes reference to the money supply.

It then follows that in a rational-expectations equilibrium, the variables $\left\{p_{t}^{*}, P_{t}, Y_{t}, i_{t}, q_{t}, D_{t}\right\}$ must each period satisfy the relations

$$
\begin{aligned}
& \lambda\left(Y_{t}, P_{t} / P_{t-1} ; \xi_{t}\right)=\beta E_{t}\left[\lambda\left(Y_{t+1}, P_{t+1} / P_{t} ; \xi_{t+1}\right)\left(1+i_{t}\right) \frac{P_{t}}{P_{t+1}}\right], \\
& \sum_{T=t}^{\infty} \beta^{T} E_{t}\left[\lambda\left(Y_{T}, P_{T} / P_{T-1} ; \xi_{T}\right) Y_{T}+\mu\left(Y_{T}, P_{T} / P_{T-1} ; \xi_{T}\right)\right]<\infty
\end{aligned}
$$




$$
\begin{gathered}
\lim _{T \rightarrow \infty} \beta^{T} E_{t}\left[\lambda\left(Y_{T}, P_{T} / P_{T-1} ; \xi_{T}\right) D_{T} / P_{T}\right]=0, \\
q_{t}^{\prime}=\frac{P_{t}}{\lambda\left(Y_{t}, P_{t} / P_{t-1} ; \xi_{t}\right)} \sum_{T \geq t+1} \beta^{T-t} E_{t} \lambda\left(Y_{T}, P_{T} / P_{T-1} ; \xi_{T}\right)\left[P_{T}^{-1} a_{T}^{\prime}+b_{T}^{\prime}\right] \prod_{s=t+1}^{T-1} F_{s}, \\
E_{t}\left\{\sum_{T=t}^{\infty}(\alpha \beta)^{T-t} \lambda\left(Y_{T}, P_{T} / P_{T-1} ; \xi_{T}\right) P_{T}^{-1} \tilde{\Pi}_{1}\left(p_{t}^{*}, p_{t}^{*}, P_{T} ; Y_{T}, P_{T} / P_{T-1}, \tilde{\xi}_{T}\right)\right\}=0,
\end{gathered}
$$

along with relations (1.9), (1.10), and (1.16) as before. Note that none of these equations involve the variables $\left\{M_{t}, \omega_{t}^{m}, \omega_{t}^{f}\right\}$, nor do they involve the functions $\psi, \omega^{m}$, or $\omega^{f}$.

Furthermore, this is the complete set of restrictions on these variables that are required in order for them to be consistent with a rational-expectations equilibrium. For given any processes $\left\{p_{t}^{*}, P_{t}, Y_{t}, i_{t}, q_{t}, D_{t}\right\}$ that satisfy the equations just listed in each period, the implied path of the money supply is given by (1.11), which clearly has a solution; and this path for the money supply necessarily satisfies (1.3) and the complementary slackness condition, as a result of our assumptions about the form of the function $\psi$. Similarly, the implied composition of the central-bank portfolio and of the public debt at each point in time are given by (1.12) and (1.17). We then have a set of processes that satisfy all of the requirements for a rationalexpectations equilibrium, and the result is established.

\subsection{Discussion}

This proposition implies that neither the extent to which quantitative easing is employed when the zero bound binds, nor the nature of the assets that the central bank may purchase through open-market operations, has any effect on whether a deflationary price-level path will represent a rational-expectations equilibrium. Hence the notion that expansions of the monetary base represent an additional tool of policy, independent of the specification of the rule for adjusting short-term nominal interest rates, is not supported by our general-equilibrium analysis of inflation and output determination. If the commitments of policymakers regarding the rule by which interest rates will be set on the one hand, and the rule which total private-sector claims on the government will be allowed to grow on the

other, are fully credible, then it is only the choice of those commitments that matters. Other 
aspects of policy should matter in practice, then, only insofar as they help to signal the nature of policy commitments of the kind just mentioned.

Of course, the validity of our result depends on the reasonableness of our assumptions, and these deserve further discussion. Like any economic model, ours abstracts from the complexity of actual economies in many respects. This raises the question whether we may have abstracted from features of actual economies that are crucial for a correct understanding of the issues under discussion.

Many readers may suspect that an important omission is the neglect of "portfolio-balance effects," which play an important role in much recent discussion of the policy options that would remain available to the Fed in the event that the zero bound is reached by the federal funds rate. ${ }^{16}$ The idea is that a central bank should be able to lower longer-term interest rates even when overnight rates are already at zero, through purchases of longer-maturity government bonds, shifting the composition of the public debt in the hands of the public in a way that affects the term structure of interest rates. (As it is generally admitted in such discussions that base money and very short-term Treasury securities have become nearperfect substitutes once short-term interest rates have fallen to zero, the desired effect should be achieved equally well by a shift in the maturity structure of Treasury securities held by the central bank, without any change in the monetary base, as by an open-market purchase of long bonds with newly created base money.)

There are evidently no such effects in our model, resulting either from central-bank securities purchases or debt management by the Treasury. But this is not, as some might expect, because we have simply assumed that bonds of different maturities (or for that matter, other kinds of assets that the central bank might choose to purchase instead of the shortest-maturity Treasury bills) are perfect substitutes. Our framework allows for different assets that the central bank may purchase to have different risk characteristics (different state-contingent returns), and our model of asset-market equilibrium incorporates those term premia and risk premia that are consistent with the absence of arbitrage opportunities.

\footnotetext{
${ }^{16}$ See, e.g., Clouse et al. (2003) and Orphanides (2003).
} 
Our conclusion differs from the one in the literature on portfolio-balance effects for a different reason. The classic theoretical analysis of portfolio-balance effects assumes a representative investor with mean-variance preferences. This has the implication that if the supply of assets that pay off disproportionately in certain states of the world is increased (so that the extent to which the representative investor's portfolio pays off in those states must also increase), the relative marginal valuation of income in those particular states is reduced, resulting in a lower relative price for the assets that pay off in those states. But in our general-equilibrium asset-pricing model, there is no such effect. The marginal utility to the representative household of additional income in a given state of the world depends on the household's consumption in that state, not on the aggregate payoff of its asset portfolio in that state. And changes in the composition of the securities in the hands of the public don't change the state-contingent consumption of the representative household - this depends on equilibrium output, and while output is endogenous, we have shown that the equilibrium relations that determine it do not involve the functions $\psi, \omega^{m}$, or $\omega^{f} .17$

Our assumption of complete financial markets and no limits on borrowing against future income may also appear extreme. However, the assumption of complete financial markets is only a convenience, allowing us to write the budget constraint of the representative household in a simple way. Even in the case of incomplete markets, each of the assets that is traded will be priced according to (1.14), where the stochastic discount factor is given by (1.8), and once again there will be a set of relations to determine output, goods prices, and asset prices that do not involve $\psi, \omega^{m}$, or $\omega^{f}$. The absence of borrowing limits is also innocuous, at least in the case of a representative-household model, since in equilibrium the representative household must hold the entire net supply of financial claims on the government; as long as the fiscal rule (1.16) implies positive government liabilities at each date, then, any borrowing

\footnotetext{
${ }^{17}$ Our general-equilibrium analysis is in the spirit of the irrelevance proposition for open-market operations of Wallace (1981). Wallace's analysis is often supposed to be of little practical relevance for actual monetary policy because his model is one in which money serves only as a store of value, so that it is not possible for there to be an equilibrium in which money is dominated in rate of return by short-term Treasury securities, something that is routinely observed. However, in the case of open-market operations that are conducted at the zero bound, the liquidity services provided by money balances at the margin have fallen to zero, so that an analysis of the kind proposed by Wallace is correct.
} 
limits that might be assumed can never bind in equilibrium. Borrowing limits can matter more in the case of a model with heterogeneous households. But in this case, the effects of open-market operations should depend not merely on which sorts of assets are purchased and which sorts of liabilities are issued to finance the purchases, but also on the way in which the central bank's trading profits are eventually rebated to the private sector (with what delay, and how distributed across the heterogeneous households), as a result of the specification of fiscal policy. The effects will not be mechanical consequences of the change in the composition of the assets in the hands of the public, but instead will result from the fiscal transfers to which the transaction gives rise; and it is unclear how quantitatively significant such effects should be.

Indeed, leaving aside the question of whether there exists a clear theoretical foundation for the existence of portfolio-balance effects, there is not a great deal of empirical support for quantitatively significant effects. The attempt of the U.S. to separately target short-term and long-term interest rates under "Operation Twist" in the early 1960's is generally regarded as having had a modest effect at best on the term structure. ${ }^{18}$ The empirical literature that has sought to estimate the effects of changes in the composition of the public debt on relative yields has also, on the whole, found effects that are not quantitatively large when present at all. ${ }^{19}$ For example, Agell and Persson (1992) summarize their findings as follows: "It turned out that these effects were rather small in magnitude, and that their numerical values were highly volatile. Thus the policy conclusion to be drawn seems to be that there is not much scope for a debt management policy aimed at systematically affecting asset yields."

Moreover, even if one supposes that large enough changes in the composition of the portfolio of securities left in the hands of the private sector can substantially affect yields, it is not clear how relevant such an effect should be for real activity and the evolution of

\footnotetext{
${ }^{18}$ Okun (1963) and Modigliani and Sutch (1967) are important early discussions that reached this conclusion. Meulendyke (1998) summarizes the literature, and finds that the predominant view is that the effect was minimal.

${ }^{19}$ Examples of studies finding either no effects or only quantitatively unimportant ones include Mogigliani and Sutch (1967), Frankel (1985), Agell and Persson (1992), Wallace and Warner (1996), and Hess (1999). Roley (1982) and Friedman (1992) find somewhat larger effects.
} 
goods prices. For example, Clouse et al. (2003) argue that a sufficiently large reduction in the number of long-term Treasuries in the hands of the public should be able to lower the market yield on those securities relative to short rates, owing to the fact that certain institutions will find it important to hold long-term Treasury securities even when they offer an unfavorable yield. ${ }^{20}$ But even if this is true, the fact that these institutions have idiosyncratic reasons to hold long-term Treasuries - and that, in equilibrium, no one else holds any or plays any role in pricing them - means that the lower observed yield on long-term Treasuries may not correspond to any reduction in the perceived cost of long-term borrowing for other institutions. If one is able to reduce the long bond rate only by decoupling it from the rest of the structure of interest rates, and from the cost of financing long-term investment projects, it is unclear that such a reduction should do much to stimulate economic activity or to halt deflationary pressures.

Hence we are not inclined to suppose that our irrelevance proposition represents so poor an approximation to reality as to deprive it of practical relevance. Even if the effects of open-market operations under the conditions described in the proposition are not exactly zero, it seems unlikely that they should be large. In our view, it is more important to note that our irrelevance proposition depends on an assumption that interest-rate policy is specified in a way that implies that these open-market operations have no consequences for interest-rate policy, either immediately (which is trivial, since it would not be possible for them to lower current interest rates, which is the only effect that would be desired), or at any subsequent date either. We have also specified fiscal policy in a way that implies that the contemplated open-market operations have no effect on the evolution of total government liabilities $\left\{D_{t}\right\}$ either - again, neither immediately nor at any later date. While we think that these definitions make sense, as a way of isolating the pure effects of open-market purchases of assets by the central bank from either interest-rate policy on the one hand and from fiscal policy on the other, it is important to note that someone who recommends

\footnotetext{
${ }^{20}$ Cecchetti (2003) similarly argues that it should be possible for the Fed to independently affect long-bond yields if it is determined to do so, given that it can print money without limit to buy additional long-term Treasuries if necessary.
} 
monetary expansion by the central bank may intend for this to have consequences of one or both of these other sorts.

For example, when it is argued that surely nominal aggregate demand could be stimulated by a "helicopter drop of money", the thought experiment that is usually contemplated is not simply a change in the function $\psi$ in our policy rule (1.11). First of all, it is typically supposed that the expansion of the money supply will be permanent. If this is the case, then the function $\phi$ that defines interest-rate policy is also being changed, in a way that will become relevant at some future date, when the money supply no longer exceeds the satiation level. ${ }^{21}$ Second, the assumption that the money supply is increased through a "helicopter drop" rather than an open-market operation implies a change in fiscal policy as well. The operation increases the value of nominal government liabilities, and it is generally at least tacitly assumed that this is a permanent increase as well. Hence the experiment that is imagined is not one that our irrelevance proposition implies should have no effect on the equilibrium path of prices.

Even more importantly, we should stress that our irrelevance result applies only given a correct private-sector understanding of the central bank's commitments regarding future policy, which may not be present. We have just argued that the key to lowering long-term interest rates, in a way that actually provides an incentive for increased spending, is by changing expectations regarding the likely future path of short rates, rather than through intervention in the market for long-term Treasuries. As a logical matter, this need not require any open-market purchases of long-term Treasuries at all. Nonetheless, the private sector may be uncertain about the nature of the central bank's policy commitment, and so may scrutinize the bank's current actions for further clues. In practice, the management

${ }^{21}$ This explains the apparent difference between our result and the one obtained by Auerbach and Obstfeld (2003) in a similar model. These authors assume explicitly that an increase in the money supply while the zero bound binds carries with it the implication of a permanently higher money supply, and also that there exists a future date at which the zero bound ceases to bind, so that the higher money supply will imply a different interest-rate policy at that later date. Clouse et al. (2003) also stress that maintenance of the higher money supply until a date at which the zero bound would not otherwise bind represents one straightforward channel through which open markets operations while the zero bound is binding could have a stimulative effect, though they discuss other possible channels as well. 
of private-sector expectations is an art of considerable subtlety, and shifts in the portfolio of the central bank could be of some value in making credible to the private sector the central bank's own commitment to a particular kind of future policy, as we discuss further in section 6. "Signalling" effects of this kind are often argued to be an important reason for the effectiveness of interventions in foreign-exchange markets, and might well provide a justification for open-market policy when the zero bound binds. ${ }^{22}$

We do not wish, then, to argue that asset purchases by the central bank are necessarily pointless under the circumstances of a binding zero lower bound on short-term nominal interest rates. However, we do think it important to observe that insofar as such actions can have any effect, it is not because of any necessary or mechanical consequence of the shift in the portfolio of assets in the hands of the private sector itself. Instead, any effect of such actions must be due to the way in which they change expectations regarding future interest-rate policy, or, perhaps, the future evolution of total nominal government liabilities. In sections 6 and 7 we discuss reasons why open-market purchases by the central bank might plausibly have consequences for expectations of these types. But since it is only through effects on expectations regarding future policy that these actions can matter, we shall focus our attention on the question of what kind of commitments regarding future policy are in fact to be desired. And this question can be addressed without explicit consideration of the role of open-market operations by the central bank of any kind. Hence we shall simplify our model - abstracting from monetary frictions and the structure of government liabilities altogether - and instead consider how it is desirable for interest-rate policy to be conducted, and what kind of commitments about this policy it is desirable to make in advance.

\section{How Severe a Constraint is the Zero Bound?}

We turn now to the question of the way in which the existence of the zero bound restricts the degree to which a central bank's stabilization objectives, with regard to both inflation and

\footnotetext{
${ }^{22}$ Clouse et al. (2003) argue that this is one important channel through which open-market operations can be effective.
} 
real activity, can be achieved, even under ideal policy. It follows from our discussion in the previous section that the zero bound does represent a genuine constraint. The differences among alternative policies that are relevant to the degree to which stabilization objectives are achieved having only to do with the implied evolution of short-term nominal interest rates, and the zero bound obviously constrains the ways in which this instrument can be used, though it remains to be seen how relevant this constraint may be.

Nonetheless, we shall see that it is not at all the case that there is nothing that a central bank can do to mitigate the severity of the destabilizing impact of the zero bound. The reason is that inflation and output do not depend solely upon the current level of short-term nominal interest rates, or even solely upon the history of such rates up until the current time (so that the current level of interest rates would be the only thing that could possibly changed in response to an unanticipated disturbance). The expected character of future interest-rate policy is also a critical determinant of the degree to which the central bank achieves its stabilization objectives, and this allows an important degree of scope for policy to be improved upon, even when there is little choice about the current level of short-term interest rates.

In fact, the management of expectations is the key to successful monetary policy at all times, and not just in those relatively unusual circumstances when the zero bound is reached. The effectiveness of monetary policy has little to do with the direct effect of changing the level of overnight interest rates, since the current cost of maintaining cash balances overnight is of fairly trivial significance for most business decisions. What actually matters is the private sector's anticipation of the future path of short rates, as this determines equilibrium longterm interest rates, as well as equilibrium exchange rates and other asset prices - all of which are quite relevant for many current spending decisions, hence for optimal pricing behavior as well. The way in which short rates are managed matters because of the signals that it gives about the way in which the private sector can expect them to be managed in the future. But there is no reason to suppose that expectations regarding future monetary policy, and hence expectations regarding the future evolution of nominal variables more generally, should 
change only insofar as the current level of overnight interest rates changes. A situation in which there is no decision to be made about the current level of overnight rates (as in Japan at present) is one which brings the question of what expectations regarding future policy one should wish to create more urgently to the fore, but this is in fact the correct way to think about sound monetary policy at all times.

Of course, there is no question to be faced about what future policy one should wish for people to expect if there is no possibility of committing oneself to a different sort of policy in the future than one would otherwise have pursued, as a result of the constraints that are currently faced (and that make desirable the change in expectations). This means that the private sector must be convinced that the central bank will not conduct policy in a way that is purely forward-looking, i.e., taking account at each point in time only of the possible paths that the economy could follow from that date onward. For example, we will show that it is undesirable for the central bank to pursue a certain inflation target, once the zero bound is expected no longer to prevent it from being achieved, even in the case that the pursuit of this target would be optimal if the zero bound did not exist (or would never bind under an optimal policy). The reason is that an expectation that the central bank will pursue the fixed inflation target after the zero bound ceases to bind gives people no reason to hold the kind of expectations, while the bound is binding, that would mitigate the distortions created by it. A history-dependent inflation target ${ }^{23}$ — if the central bank's commitment to it can be made credible - can instead yield a superior outcome.

But this too is an important feature of optimal policy rules more generally (see, e.g., Woodford, 2003, chapter 7). Hence the analytical framework and institutional arrangements used to make monetary policy need not be changed in any fundamental way in order to deal with the special problems created by a "liquidity trap". As we explain in section 4, the optimal policy in the case of a binding zero bound can be implemented through a targeting procedure that represents a straightforward generalization of a policy that would be optimal

\footnotetext{
${ }^{23}$ As we shall see, it is easier to explain the nature of the optimal commitment if it is described as a history-dependent price-level target.
} 
even if the zero bound were expected never to bind.

\subsection{Feasible Responses to Fluctuation in the Natural Rate of In- terest}

In order to characterize the way in which stabilization policy is constrained by the zero bound, we shall make use of a log-linear approximation to the structural equations of section 2, of a kind that is often employed in the literature on optimal monetary stabilization policy. ${ }^{24}$ Specifically, we shall log-linearize the structural equations of our model (except for the zero bound (1.4)) around the paths of inflation, output and interest rates associated with a zeroinflation steady state, in the absence of disturbances $\left(\xi_{t}=0\right)$. We choose to expand around these particular paths because the zero-inflation steady state represents optimal policy in the absence of disturbances. ${ }^{25}$ In the event of small enough disturbances, optimal policy will still involve paths in which inflation, output and interest rates are at all times close to those of the zero-inflation steady state. Hence an approximation to our equilibrium conditions that is accurate in the case of inflation, output and interest rates near those values will allow an accurate approximation to the optimal responses to disturbances in the case that the disturbances are small enough.

In the zero-inflation steady state, it is easily seen that the real rate of interest is equal to $\bar{r} \equiv \beta^{-1}-1>0$, and this is also the steady-state nominal interest rate. Hence in the case of small enough disturbances, optimal policy will involve a nominal interest rate that is always positive, and the zero bound will not be a binding constraint. (Optimal policy in this case is characterized in the references cited in the previous paragraph.) However, we are interested in the case in which disturbances are at least occasionally large enough for the zero bound to

\footnotetext{
${ }^{24}$ See, e.g., Clarida et al., (1999) or Woodford (2003). Jung et al. (2001), Sugo and Teranishi (2003), and Adam and Billi (2003) also consider optimal policy in the presence of the zero bound in frameworks like the one used here.

${ }^{25}$ See Woodford (2003, chapter 7) for more detailed discussion of this point. The fact that zero inflation is optimal, rather than mild deflation, depends on our abstracting from transactions frictions, as discussed further in footnote xx below. As shown by Woodford, a long-run inflation target of zero is optimal in this model, even when the steady-state output level associated with zero inflation is suboptimal, owing to market power.
} 
bind, i.e., for it to prevent attainment of the outcome that would be optimal in the absence of such a bound. A case in which it is possible to rigorously consider this problem using only a log-linear approximation to the structural equations is that in which we suppose that the lower bound on nominal interest is not much below $\bar{r}$. We can arrange for this gap to be as small as we may wish, without changing other crucial parameters of the model such as the assumed rate of time preference, by supposing that interest is paid on the monetary base at a rate $i^{m} \geq 0$ that cannot (for some institutional reason) be reduced. Then the lower bound on interest rates actually becomes

$$
i_{t} \geq i^{m}
$$

We shall characterize optimal policy subject to a constraint of the form (2.1), in the case that both a bound on the amplitude of disturbances $\|\xi\|$ and the size of the steady-state opportunity cost of holding money $\bar{\delta} \equiv\left(\bar{r}-i^{m}\right) /(1+\bar{r})>0$ are small enough. Specifically, both our structural equations and our characterization of the optimal responses of inflation, output and interest rates to disturbances will be required to be exact only up to a residual of order $\mathcal{O}\left(\|\xi, \bar{\delta}\|^{2}\right)$. We shall then hope (without here seeking to verify this) that our characterization of optimal policy in the case of a small opportunity cost of holding money and small disturbances is not too inaccurate in the case of an opportunity cost of several percentage points (the case in which $i^{m}=0$ ) and disturbances large enough to cause the natural rate of interest to vary by several percentage points (as will be required in order for the zero bound to bind).

As shown in Woodford (2003), the log-linear approximate equilibrium relations may be 
summarized by two equations each period, ${ }^{26}$ a forward-looking "IS relation"

$$
x_{t}=E_{t} x_{t+1}-\sigma\left(i_{t}-E_{t} \pi_{t+1}-r_{t}^{n}\right),
$$

and a forward-looking "AS relation" (or "New Keynesian Phillips curve")

$$
\pi_{t}=\kappa x_{t}+\beta E_{t} \pi_{t+1}+u_{t}
$$

Here $\pi_{t} \equiv \log \left(P_{t} / P_{t-1}\right)$ is the inflation rate, $x_{t}$ is a welfare-relevant output gap, and $i_{t}$ is now the continuously compounded nominal interest rate (corresponding to $\log \left(1+i_{t}\right)$ in the notation of section 2). The terms $u_{t}$ and $r_{t}^{n}$ are composite exogenous disturbance terms that shift the two equations; the former is commonly referred to as a "cost-push disturbance", while the latter indicates exogenous variation in the Wicksellian "natural rate of interest", i.e., the equilibrium real rate of interest in the case that output is at all times equal to the natural rate of output. The coefficients $\sigma$ and $\kappa$ are both positive, while $0<\beta<1$ is again the utility discount factor of the representative household.

Equation (2.2) is a log-linear approximation to (1.2), while (2.3) is derived by $\log$ linearizing $(1.7)-(1.9)$ and then eliminating $\log \left(p_{t}^{*} / P_{t}\right)$. We omit the log-linear version of the money-demand relation (1.3), since we are here interested solely in characterizing the possible equilibrium paths of inflation, output, and interest rates, and we may abstract from the question of what the required path for the monetary base may be that is associated with any such equilibrium in considering this. (It suffices that there exist a monetary base

\footnotetext{
${ }^{26}$ Here we omit the equilibrium relation implied by the government budget constraint. We assume the existence of lump-sum taxes, so that the government budget constraint implies no additional restrictions on the set of rational-expectations equilibria that can be brought about (assuming that fiscal policy is adjusted appropriately, in order to be consistent with the optimal monetary policy). And in our positive analysis of the consequences of alternative monetary policy rules, we assume a (locally) Ricardian fiscal policy, as discussed in Woodford (2003, chap. 4, sec. 4), so that intertemporal government solvency plays no role in the determination of equilibrium inflation. Our conclusions do, however, depend on these assumptions. In the case of a non-Ricardian fiscal policy which the central bank is unable to change, Iwamura and Watanabe (2002) show that there is an equilibrium relation between current and expected future inflation, such that less deflation immediately would require more deflation later — a result analogous to the "unpleasant monetarist arithmetic" of Sargent and Wallace (1981). In this case, our conclusion that a commitment to a higher pricelevel target in the future can reduce deflation immediately would not be correct. It must be understood in all of our discussion below that our recommendations regarding monetary policy depend on the possibility of a fiscal policy compatible with the equilibrium that the central bank seeks to achieve.
} 
that will satisfy the money-demand relation in each case, and this will be true as long as the interest-rate bound is satisfied.) The other equilibrium requirements of section 2 can be ignored in the case that we are interested only in possible equilibria that remain forever near the zero-inflation steady state, as they are automatically satisfied in that case.

Equations $(2.2)-(2.3)$ represent a pair of equations each period to determine inflation and the output gap, given the central bank's interest-rate policy. We shall seek to compare alternative possible paths for inflation, the output gap, and the nominal interest rate that satisfy these two log-linear equations together with the inequality (2.1). Note that our conclusions will be identical (up to a scale factor) in the event that we multiply the amplitude of the disturbances and the steady-state opportunity cost $\bar{\delta}$ by any common factor; alternatively, if we measure the amplitude of disturbances in units of $\bar{\delta}$, our results will be independent of the value of $\bar{\delta}$ (to the extent that our log-linear approximation remains valid). Hence we choose the normalization $\bar{\delta}=1-\beta$, corresponding to $i^{m}=0$, to simplify the presentation of our results. In the case, the lower bound for the nominal interest rate is again given by (1.4).

\subsection{Deflation under Forward-Looking Policy}

We begin by considering the degree to which the zero bound impedes the achievement of the central bank's stabilization objectives in the case that the bank pursues a strict inflation target. We interpret this as a commitment to adjust the nominal interest rate so that

$$
\pi_{t}=\pi^{*}
$$

each period, insofar as it is possible to achieve this with some non-negative interest rate. It is easy to verify, by the IS and AS equation, that a necessary condition for this target to be satisfied is:

$$
i_{t}=r_{t}^{n}+\pi^{*}
$$

When inflation is on target, the real rate is equal to the natural real rate at all times and the output gap at its long run level. The zero bound, however, prevents (2.5) from holding 
(a) inflation

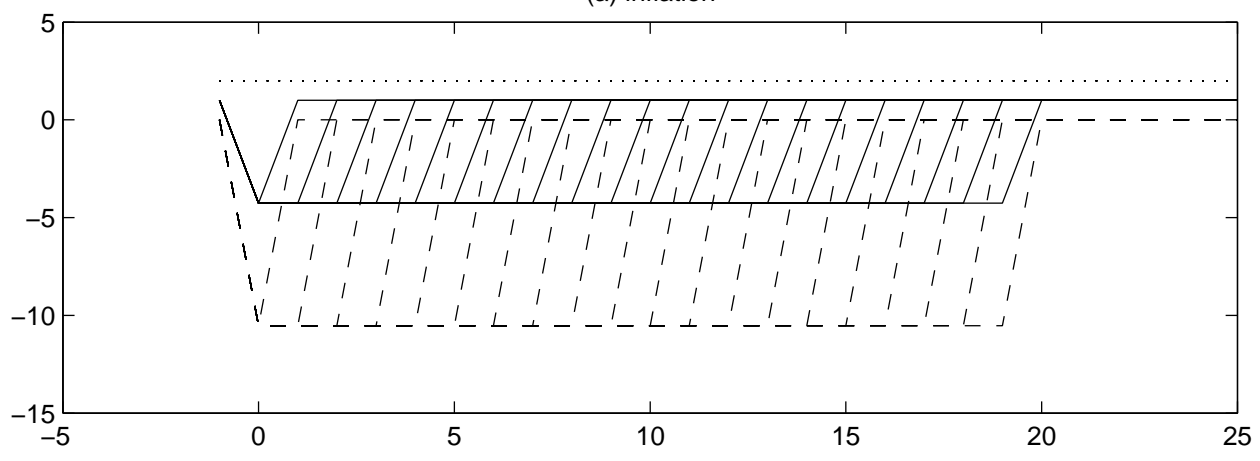

(b) output gap

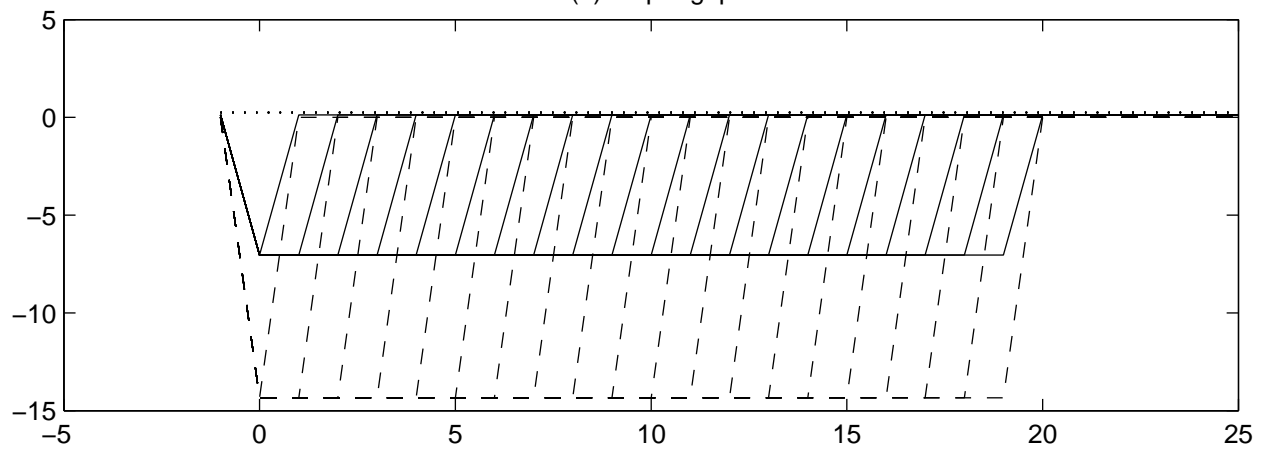

Figure 2: Dynamics of inflation and the output gap under strict inflation targeting, for three alternative inflation targets.

if $r_{t}^{n}<-\pi^{*}$. Thus if the natural rate of interest is low, the zero bound frustrates the Central Bank's ability to implement an inflation target. Suppose the inflation target is zero so that $\pi^{*}=0$. Then the zero bound is binding if the natural rate of interest is negative, and the Central Bank is unable to achieve its inflation target.

To illustrate this, let us consider the following experiment: Suppose the natural rate of interest is unexpectedly negative in period 0 and reverts back to the steady-state value $\bar{r}>0$ with a fixed probability in every period. Figure 2 shows the state-contingent paths of the output gap and inflation in the case of three different possible inflation targets $\pi^{*}$. In the figure we assume in period 0 that the natural rate of interest becomes -2 percent per annum and then reverts back to the steady-state value of +4 percent per annum with a probability 0.1 each quarter. Thus the natural rate of interest is expected to be negative for 10 quarters on average at the time that the shock occurs. 
The dashed lines in Figure 2 show the state-contingent evolution of the output gap and inflation if the central bank targets zero inflation. ${ }^{27}$ The first dashed line shows the equilibrium if the natural rate of interest returns back to steady state in period 1 , the next line if it returns in period 2, and so on. The inability of the central bank to set a negative nominal interest rate results in a 12 percent per output gap and 9 percent annual deflation. Since there is a 90 percent chance of the natural rate of interest to remain negative for the next quarter, this creates expectation of future deflation and negative output gap which creates even further deflation. Even if the central bank lowers the short-term nominal interest rate to zero the real rate of return is positive because the private sector expects deflation. The solid line in the figure shows the equilibrium if the central bank targets a one percent inflation target. In this case the private sector expect one percent inflation once out of the trap. This, however, is not enough to offset the minus two percent negative natural rate of interest, so that in equilibrium the private sector expect deflation instead of inflation. The result of this and a negative natural rate of interest is 3 percent annual deflation (when the natural rate of interest is negative) and an output gap of more than 5 percent.

Finally the dotted line shows the evolution of output and inflation if the central bank targets 2 percent inflation. In this case the central bank can satisfy equation (3.14) even when the natural rate of interest in negative. When the natural rate of interest is minus two percent, the central bank lowers the nominal interest rate to zero. Since the inflation target is two percent, the real rate is minus two percent, which is enough to close the output gap and keep inflation on target. If the inflation target is high enough, therefore, the central bank is able to accommodate a negative natural rate of interest. This is the argument given by Phelps (1972), Summers (1991), and Fischer (1996) for a positive inflation target. Krugman

\footnotetext{
${ }^{27}$ In our numerical analysis, we interpret periods as quarters, and assume coefficient values of $\sigma=0.5$, $\kappa=0.02$, and $\beta=0.99$. The assumed value of the discount factor implies a long-run real rate of interest of $\bar{r}$ equal to four percent per annum, as noted in the text. The assumed value of $\kappa$ is consistent with the empirical estimate of Rotemberg and Woodford (1997). The assumed value of $\sigma$ represents a relatively low degree of interest-sensitivity of aggregate expenditure. We prefer to bias our assumptions in the direction of only a modest effect of interest rates on the timing of expenditure, so as not to exaggerate the size of the output contraction that is predicted to result from an inability to lower interest rates when the zero bound binds. As Figure 2 shows, even for this value of $\sigma$, the output contraction that results from a slightly negative value of the natural rate of interest is quite substantial.
} 
(1998) makes a similar argument, and suggests more concretely that Japan needs a positive inflation target of 4 percent under its current circumstances to achieve negative real rates and curb deflation.

While we see that commitment to a higher inflation target will indeed guard against the need for a negative output gap in periods when the natural rate of interest falls, the price of this solution is the distortions created by the inflation, both when the natural rate of interest is negative and under more normal circumstances as well. Hence the optimal inflation target (from among the strict inflation targeting policies just considered) will be some value that is at least slightly positive, in order to mitigate the distortions created by the zero bound when the natural rate of interest is negative, but not so high as to keep the zero bound from ever binding (see Table 1). In the case of an intermediate inflation target, however (like the one percent target considered in the figure), there is both a substantial recession when the natural rate of interest becomes negative, and chronic inflation at all other times. Hence no such policy allows a complete solution of the problem posed by the zero bound in the case that the natural rate of interest is sometimes negative.

Nor can one do better through commitment to any policy rule that is purely forwardlooking in the sense discussed by Woodford (2000). A purely forward-looking policy is one under which the central bank's action at any time depends only on an evaluation of the possible paths for the central bank's target variables (here, inflation and the output gap) that are possible from the current date forward - neglecting past conditions except insofar as they constrain the economy's possible evolution from here on. In the log-linear model presented above, the possible paths for inflation and the output gap from period $t$ onward depend only on the expected evolution of the natural rate of interest from period $t$ onward. If we assume a Markovian process for the natural rate, as in the numerical analysis above, then any purely forward-looking policy will result in an inflation rate, output gap, and nominal interest rate in period $t$ that depend only on the natural rate in period $t$ - in our numerical example, on whether the natural rate is still negative or has already returned to its long-run steady-state value. It is easily shown in the case of our 2-state example that the optimal 
state-contingent evolution for inflation and output from among those with this property will be one in which the zero bound binds if and only if the natural rate is in the low state; hence it will correspond to a strict inflation target of the kind just considered, for some $\pi^{*}$ between zero and two percent.

But one can actually do considerably better, through commitment to a history-dependent policy, in which the central bank's actions will depend on past conditions even though these are irrelevant to the degree to which its stabilization goals could in principle be achieved from then on. We characterize the optimal form of history-dependent policy, and determine the degree to which it improves upon the stabilization of both output and inflation, in the next section.

\subsection{The Optimal Policy Commitment}

We now characterize optimal monetary policy. We do this by optimizing over the set of all possible state-contingent paths for inflation, output and the short-term nominal interest rate consistent with the log-linearized structural relations (2.2) and (2.3), under the assumption (for now) that the expectations regarding future state-contingent policy that are required for such an equilibrium can be made credible to the private sector. In considering the central bank's optimization problem under the assumption that credible commitment is possible regarding future policy, we do not mean to minimize the subtlety of the task of actually communicating such a commitment to the public and making it credible. However, we do not believe that it makes sense to recommend a policy that would systematically seek to achieve an outcome other than a rational-expectations equilibrium - that is, we are interested in policies that will have the desired effect even when correctly understood by the public. Optimization under the assumption of credible commitment is simply a way of finding the best possible rational-expectations equilibrium. Once the equilibrium that one would like to bring about has been identified, along with the interest-rate policy that it requires, one can turn to the question of how best to signal these intentions to the public (an issue that we briefly address in section 5 below). 
We assume that the government minimizes:

$$
\min E_{0}\left\{\sum_{t=0}^{\infty} \beta^{t}\left(\pi_{t}^{2}+\lambda x_{t}^{2}\right)\right\}
$$

This loss function can be derived by a second order Taylor expansion of the utility of the representative household. ${ }^{28}$ The optimal program can be found by a Lagrangian method, extending the methods used in Clarida et al. (1999) and Woodford (1999; 2003, chapter 7) to the case in which the zero bound can sometimes bind, as shown by Jung et al. (2001). Let us combine the zero bound and the IS equation to yield the inequality:

$$
x_{t} \leq E_{t} x_{t+1}+\sigma\left(r_{t}^{n}+E_{t} \pi_{t+1}\right)
$$

The Lagrangian for this problem is then:

$$
\mathcal{L}_{0}=E_{0} \sum_{t=0}^{\infty} \beta^{t}\left\{\frac{1}{2}\left[\pi_{t}^{2}+\lambda x_{t}^{2}\right]+\phi_{1 t}\left[x_{t}-x_{t+1}-\sigma \pi_{t+1}-\sigma r_{t}^{n}\right]+\phi_{2 t}\left[\pi_{t}-\kappa x_{t}-\beta \pi_{t+1}\right]\right\}
$$

The first order conditions for an optimal policy commitment are shown by Jung et al. to be:

$$
\begin{gathered}
\pi_{t}+\phi_{2 t}-\phi_{2 t-1}-\beta^{-1} \sigma \phi_{1 t-1}=0 \\
\lambda x_{t}+\phi_{1 t}-\beta^{-1} \phi_{1 t-1}-k \phi_{2 t}=0 \\
\phi_{1 t} \geq 0, \quad i_{t} \geq 0, \quad \phi_{1 t} i_{t}=0
\end{gathered}
$$

One can not apply standard solution methods for rational expectation models to solve this system due to the complications of the nonlinear constraint (2.9). The numerical method

\footnotetext{
${ }^{28}$ See Woodford (2003, chapter 6$)$ for details. This approximation applies in the case that we abstract from monetary frictions as assumed in this section. If transactions frictions are instead non-negligible, the loss function should include an additional term proportional to This would indicate welfare gains from keeping nominal interest rates as close as possible to the zero bound (or, more generally, the lower bound $i^{m}$ ). Nonetheless, because of the stickiness of prices, it would not be optimal for interest rates to be at zero at all times, as implied by the flexible-price model discussed by Uhlig (2000). The optimal inflation rate in the absence of shocks would be slightly negative, rather than zero as in the "cashless" model considered in this section; but it would not be so low that the zero bound would be reached, except in the event of temporary declines in the natural rate of interest, as in the analysis here.

Note also that (2.6) implies that the optimal output gap is zero. More generally, there should be an output-gap stabilization objective of the form $\left(x_{t}-x *\right)^{2}$; the utility-based loss function involves $x *=0$ only if one assumes the existence of an output or employment subsidy that offsets the distortion due to the market power of firms. However, the value of $x *$ does not affect the optimal state-contingent paths derived in this section and shown in figures 3 and 4 , nor the formulas given in section 3 for the optimal targeting rule.
} 
that we use to solve these equations is described in the appendix of Eggertsson and Woodford (2003). ${ }^{29}$ Here we discuss the results that we obtain for the particular numerical experiment considered in the previous section.

What is apparent from the first order conditions (2.7)-(2.8) is that optimal policy is history dependent, so that the optimal choice of inflation, the output gap and the nominal interest rates depends on the past values of the endogenous variables. This can be seen by the appearance of lagged value of the Lagrange multipliers in the first order conditions. To get a sense of how this history dependence matters, it is useful to consider the numerical exercise from the last section: Suppose the natural rate of interest becomes negative in period 0 and then reverts back to steady state with a fixed probability in each period. ${ }^{30}$

Figure 3 shows the optimal output gap, inflation and the price level from period 0 to period 25. One observes that the optimal policy involves committing to the creation of an output boom once the natural rate again becomes positive, and hence to the creation of future inflation. Such a commitment stimulates aggregate demand and reduces deflationary pressures while the economy remains in the "liquidity trap", through each of several channels. As Krugman (1998) points out, creating the expectation of future inflation can lower real interest rates, even when the nominal interest rate cannot be reduced. In the context of Krugman's model, it might seem that this requires that inflation be promised quite quickly (by the following "period"). Our fully intertemporal model shows how even the expectation of later inflation - nominal interest rates are not expected to rise to offset it - can stimulate current demand, since in our model current spending decisions depend on real interest-rate expectations far in the future. For the same reason, the expectation that nominal interest rates will be kept low later, when the central bank might otherwise have raised them, will

\footnotetext{
${ }^{29}$ Jung et al. (2001) discuss the solution of these equations only for the case in which the number of periods for which the natural rate of interest will be negative is known with certainty at the time that the disturbance occurs. Here we show how the system can be solved in the case of a stochastic process for the natural rate of a particular kind.

${ }^{30}$ Adam and Billi (2003) instead compute the equilibrium dynamics associated with optimal policy in the case of empirically estimated disturbance processes for both the natural rate of interest and the "cost-push" term in the aggregate-supply relation. Their general findings about the character of optimal policy are similar to those obtained here.
} 
(a) inflation

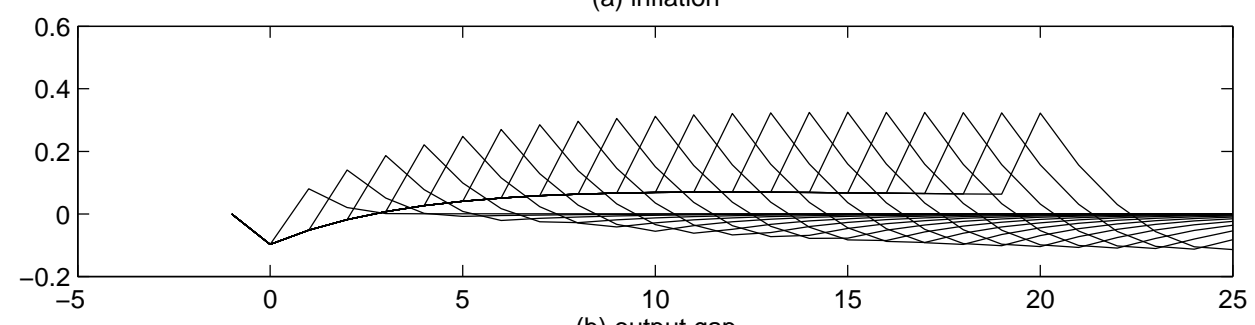

(b) output gap
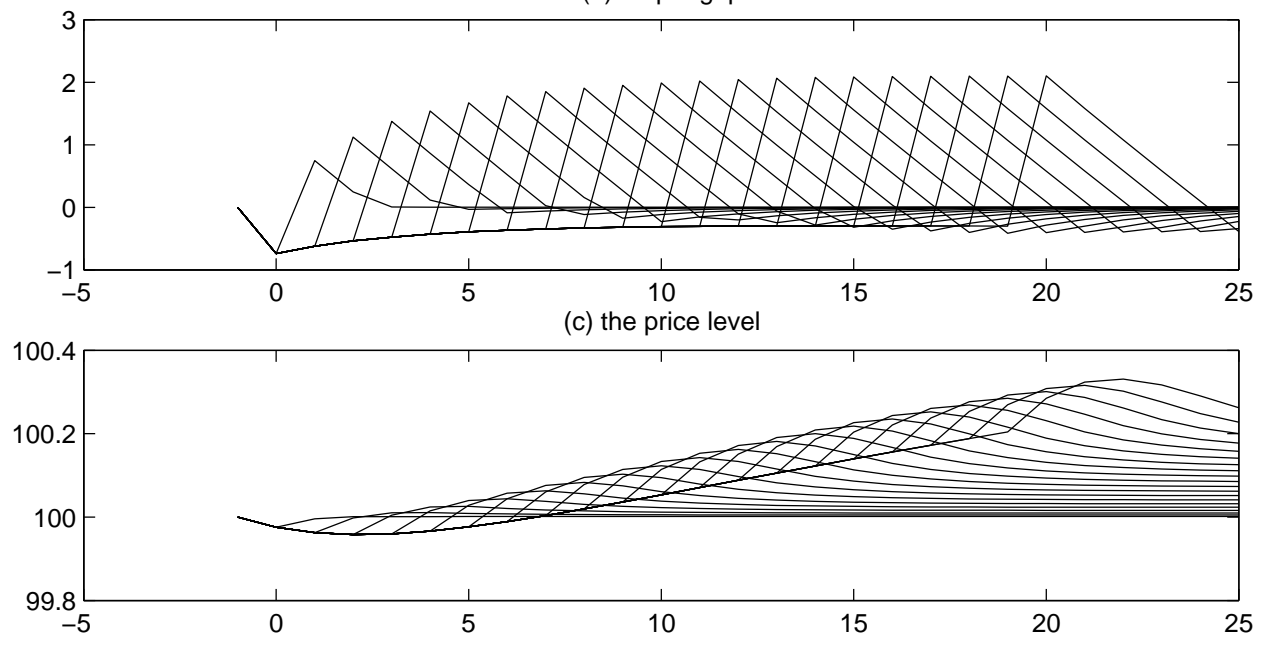

Figure 3: Dynamics of the output gap and inflation under an optimal policy commitment.

also stimulate spending while the zero bound still binds. And finally, the expectation of higher future income should stimulate current spending, in accordance with the permanent income hypothesis. In addition, prices are less likely to fall, even given the current level of real activity, insofar as future inflation is expected. This reduces the distortions created by deflation itself.

On the other hand, these gains from the change in expectations during the "trap" can be achieved (given rational expectations on the part of the private sector) only if the central bank is expected to actually pursue the inflationary policy after the natural rate returns to its normal level. This will in turn create distortions then, which limits the extent to which this tool is used under an optimal policy. Hence some contraction of output and some deflation occur during the period that the natural rate is negative, even under the optimal policy commitment. It is also worth noting that while the optimal policy involves commitment to a higher price level in the future, the price level will ultimately be stabilized. This is in 


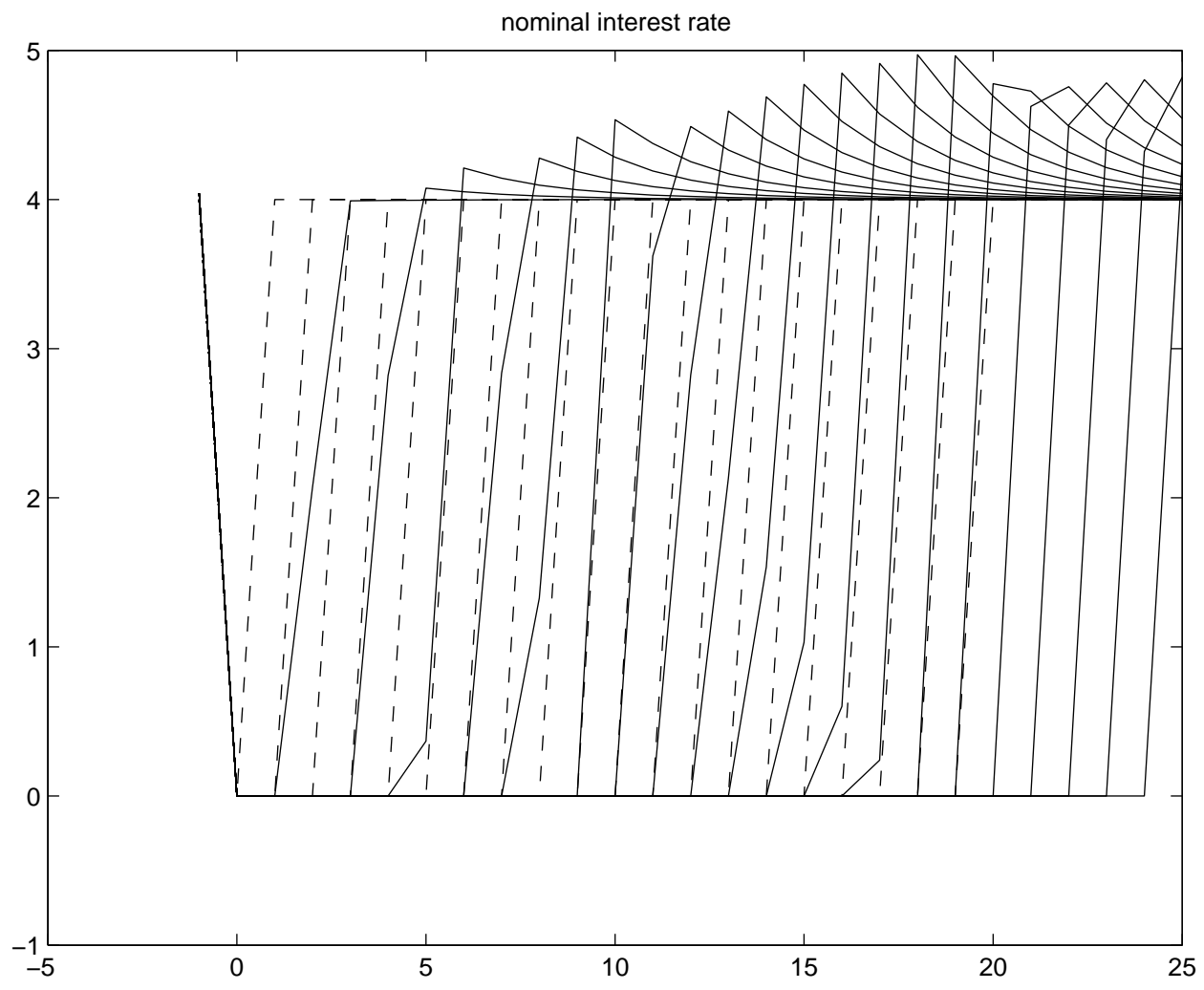

Figure 4: The associated state-contingent path of the short-term nominal interest rate, under the policy shown in Figure 3 [solid line], and under the zero inflation target shown in Figure 2 [dashed line].

sharp contrast to a constant positive inflation target that would imply an ever-increasing price level.

Figure 4 shows the corresponding state-contingent nominal interest rate under the optimal commitment, and contrasts it to the evolution of the nominal interest rate under a zero inflation target. To increase inflation expectations in the trap, the central bank commits to keeping the nominal interest rates at zero after the natural rate of interest becomes positive again. In contrast, if the central bank targets zero inflation, it raises the nominal interest rate as soon as the natural rate of interest becomes positive again. The optimal commitment is an example of history-dependent policy, in which the central bank commits to raise the interest rates slowly at the time the natural rate becomes positive in order to affect expectations when the zero bound is binding. 
(a) interest rate
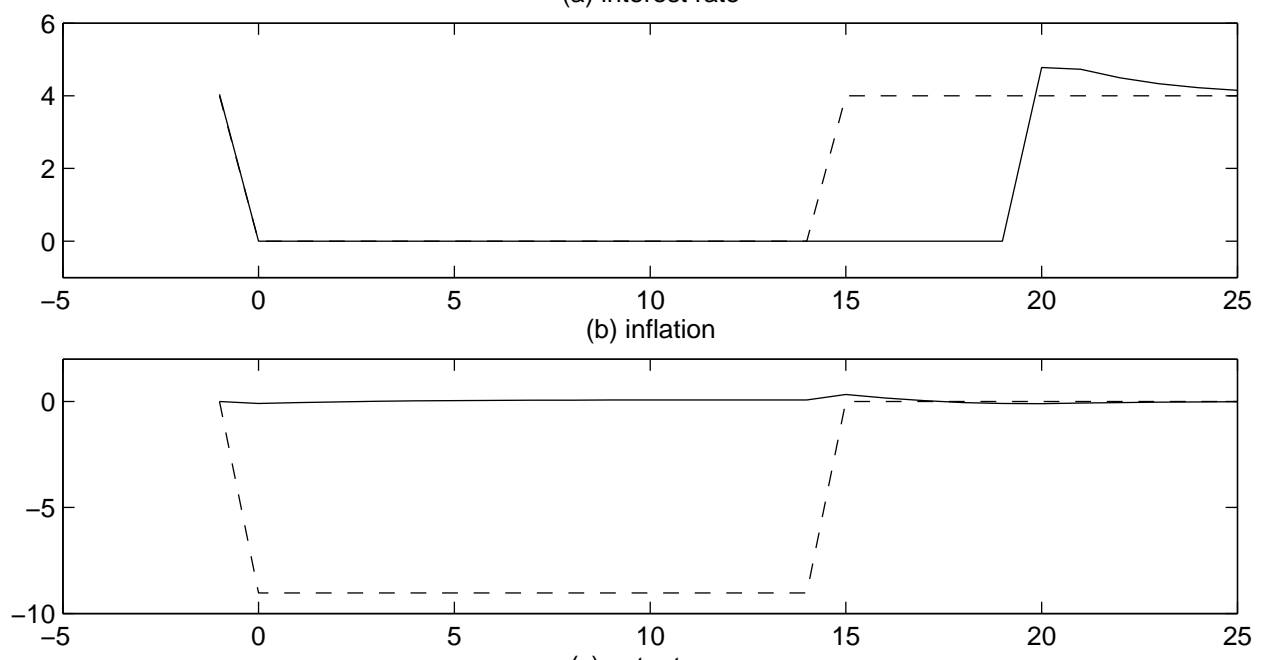

(c) output gap

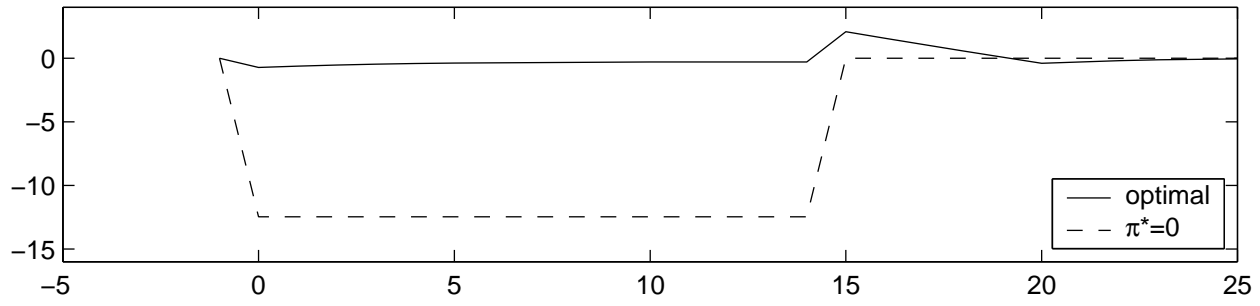

Figure 5: Comparison of the state-contingent paths under the two policies compared in Figure 4, in the case that the natural rate of interest is negative for 15 quarters.

The nature of the additional history-dependence of the optimal policy may perhaps be more easily seen if we consider the evolution of inflation, output and interest rates under a single possible realization of the random fundamentals. Figure 5 compares the equilibrium evolution of all three variables, both under the zero inflation target and under optimal policy, in the case that the natural rate of interest is negative for 15 quarters $(t=0$ through 14), though it is not known until quarter 15 that the natural rate will return to its normal level in that quarter. Under the optimal policy, the nominal interest rate is kept at zero for five more quarters $(t=15$ through 19$)$, whereas it immediately returns to its long-run steady-state level in quarter 15 under the forward-looking policy. The consequence of the anticipation of policy of this kind is that both the contraction of real activity and the deflation that occur under the strict inflation target are largely avoided, as shown in the second and third panels of the figure. 


\section{Implementing Optimal Policy}

We turn now to the question of how policy should be conducted in order to bring about the optimal equilibrium characterized in the previous section. The question of the implementation of optimal policy remains a non-trivial one, even after the optimal state-contingent evolutions of all variables have been identified, for in general the solution obtained for the optimal state-contingent path of the policy instrument (i.e., the short-term nominal interest rate) does not represent in itself a useful description of a policy rule. ${ }^{31}$ For example, in the context of the present model, a commitment to a state-contingent nominal interest-rate path, even when fully credible, does not imply determinate rational-expectations equilibrium paths for inflation and output; it is instead necessary for the central bank to be committed (and understood to be committed) to a particular way of responding to deviations of inflation and the output gap from their desired evolution. Another problem is that a complete description of the optimal state-contingent interest-rate path is unlikely to be feasible. In the previous section, we showed that it is possible to characterize (at least numerically) the optimal state-contingent interest-rate path in the case of one very particular kind of stochastic process for the natural rate of interest. But a solution of this kind allowing for all the possible states of belief about the probabilities of various future evolutions of the natural rate (and disturbances to the aggregate-supply relation as well) would be difficult to write down, let alone to explain to the public.

Here we show that optimal policy can nonetheless be implemented through commitment to a policy rule that specifies the central bank's short-run targets at each point in time as a (fairly simple) function of what has occurred prior to that date.

How can the optimal policy be implemented? One may be tempted to believe that our suggested policy is not entirely realistic or operational. Figures 3 and 4, for example, indicate that the optimal policy involves a complicated state contingent plan for the nominal interest rate, that may be hard to communicate to the public. Furthermore, it may appear that

\footnotetext{
${ }^{31}$ For further discussion in a more general context, see Woodford (2003, chapter 7).
} 
it depends on a knowledge of a special statistical process for the natural rate of interest, that is in practice hard to estimate. Our discussion of the fixed inflation target suggest that the effectiveness of increasing inflation expectation to close the output gap depends on the difference between the announced inflation target and the natural rate of interest. It may, therefore, seem crucial to estimate the natural rate of interest to implement the optimal policy. Below we show the striking result that the optimal policy rule can be implemented without any estimate or knowledge of the statistical process for the natural rate of interest. This is an example of a robustly optimal direct policy rule of the kind discussed in Giannoni and Woodford (2002) for the case of a general class of linear-quadratic policy problems. An interesting feature of the present example is that we show how to construct an robustly optimal rule in the same spirit, in a case where not all of the relevant constraints are linear (owing to the fact that the zero bound binds at some times and not at others).

\subsection{An Optimal Targeting Rule}

To implement the rule proposed here, the central bank need only observe the price level and the output gap. The rule suggested replicates exactly the history dependence discussed in the last section. The rule is implemented as follows.

[i] In each and every period, there is a predetermined price-level target $p_{t}^{*}$. The Central Bank chooses the interest rate $i_{t}$ to achieve the target relation

$$
\tilde{p}_{t} \stackrel{\prime}{=} p_{t}^{*}
$$

if this is possible; if it is not possible, even by lowering the nominal interest rate to zero, then $i_{t}=0$. Here $\tilde{p}_{t}$ is an output-gap adjusted price index, ${ }^{32}$ defined by

$$
\tilde{p}_{t} \equiv p_{t}+\frac{\lambda}{\kappa} x_{t}
$$

\footnotetext{
${ }^{32}$ On the desirability of a target for this index in the case that the zero bound does not bind, see Woodford (2003, chapter 7). This would correspond to a nominal GDP target in the case that $\lambda=\kappa$, and that the natural rate of output follows a deterministic trend. However, the utility-based loss function derived in Woodford (2003, chapter 6 ) involves $\lambda=\kappa / \theta$, where $\theta>1$ is the elasticity of demand faced by the suppliers of differentiated goods, so that the optimal weight on output is considerably less than under a nominal GDP target. Furthermore, the welfare-relevant output gap is unlikely to correspond too closely to deviations of real GDP from a deterministic trend.
} 


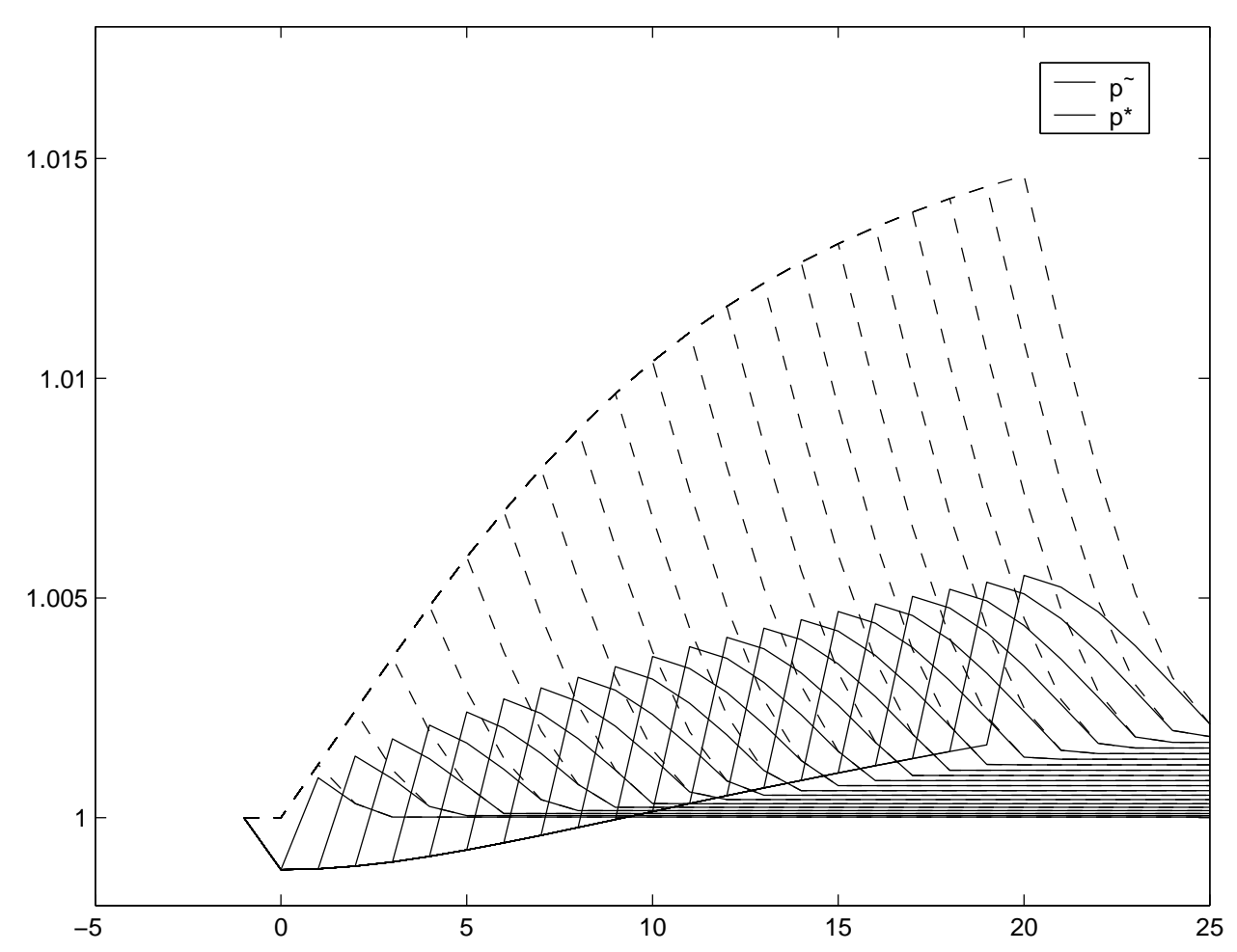

Figure 6: Responses of the price-level target and the gap-adjusted price level to a shock to the natural rate of interest.

[ii] The target for the next period is then determined as

$$
p_{t+1}^{*}=p_{t}^{*}+\beta^{-1}(1+\kappa \sigma) \Delta_{t}-\beta^{-1} \Delta_{t-1}
$$

where $\Delta_{t}$ is the target shortfall in period $t$

$$
\Delta_{t} \equiv p_{t}^{*}-\tilde{p}_{t}
$$

It can be verified that this rule does indeed achieve the optimal commitment solution. If the price-level target is not reached, because of the zero bound, the central bank increases its target for the next period. This, in turn, increases inflation expectations further in the trap, which is exactly what is needed to reduce the real interest rate.

Figure 6 shows how the price-level target $p_{t}^{*}$ would evolve over time, depending on the 
number of periods for which the natural rate of interest remains negative, in the same numerical experiment as in Figure 3. (Here the solid lines show the evolution of the gapadjusted price level $\tilde{p}_{t}$, while the dashed lines show the evolution of $p_{t}^{*}$.) One observes that the target price level is ratcheted steadily higher during the period in which the natural rate remains negative, as the actual price level continues to fall below the target by an increasing amount. Once the natural rate of interest becomes positive again, the degree to which the gap-adjusted price level undershoots the target begins to shrink, although the target often continues to be undershot (as the zero bound continues to bind) for several more quarters. (How long this is true depends on how high the target price level has risen relative to the actual index; it will be higher the longer the time for which the natural rate has been negative.) As the degree of undershooting begins to shrink, the price-level target begins to fall again, as a result of the dynamics specified by (3.11). This hastens the date at which the target can actually be hit with a non-negative interest rate. Once the target ceases to be undershot, it no longer changes, and the central bank targets and achieves a new constant value for the gap-adjusted price level $\tilde{p}_{t}$, one slightly higher than the target in place before the disturbance occurred.

Note that this approach to implementing optimal policy gives an answer to the question whether there is any point in announcing an inflation target (or price-level target) if one knows that it is extremely unlikely that in the short run it can be achieved, owing to the fact that the zero bound is likely to continue to bind. The answer here is yes. The central bank wishes to make the private sector aware of its commitment to the time-varying price-level target described by $(3.10)$ - (3.12), since eventually it will be able to hit the target, and the anticipation of that fact (i.e., of the level that the price level will eventually reach, as a result of the policies that the bank will follow after the natural rate of interest again becomes positive) while the natural rate is still negative is important in mitigating the distortions caused by the zero bound. The fact that the target is not hit immediately should not create doubts about the meaningfulness of central-bank announcements regarding its target, if it is explained that the bank is committed to hitting the target if this is possible at a non- 
negative interest rate, so that at each point in time, either the target will be attained or a zero-interest-rate policy will be followed. The existence of the target is relevant even when it is not being attained, as it allows the private sector to judge how close the central bank is to a situation in which it would feel justified in abandoning the zero-interest-rate policy; hence the current gap between the actual and target price level should shape private-sector expectations of the time for which interest rates are likely to remain low. ${ }^{33}$

Would the private sector have any reason to believe that the central bank was serious about the price-level target, if each period all that is observed is a zero nominal interest rate and yet another target shortfall? The best way of making a rule credible is for the central bank to conduct policy over time in a way that demonstrates its commitment. Ideally, the central bank's commitment to the price-level targeting framework would be demonstrated before the zero bound came to bind (at which time the central bank would have frequent opportunities to show that the target did determine its behavior). The rule proposed above is one that would be equally optimal under normal circumstances as in the case of the relatively unusual kind of disturbance that causes the natural rate of interest to be substantially negative.

To understand how the rule works out of the trap it is useful to note that when the nominal interest rate is positive, $\Delta_{t}=0$ at all times. The central bank, therefore, should demonstrate a commitment to subsequently undo overshoots and undershoots of the pricelevel target. In this case, deflation that occurs when the economy finds itself in a liquidity trap should create expectations of future inflation, as mandated by optimal policy. The additional term $\Delta_{t}$ implies that when the zero bound is binding, the central bank should raise its long-run price-level target even further, thus increasing inflation expectations even

\footnotetext{
${ }^{33}$ An interesting feature of the optimal rule is that it involves history-dependence that cannot be summarized solely by the outcomes that the central bank has been able to achieve in the past; it matters to what it extent the zero bound has prevented the central bank from pursuing as stimulative a policy as it otherwise would have done. In this respect, the optimal policy rule derived here is similar to the rules advocated by Reifschneider and Williams (2000), under which the interest-rate operating target at each point in time should depend on how low the central bank would have lowered interest rates in the past had the zero bound not prevented this. Sugo and Teranishi (2003) show that optimal policy rules are of the form discussed by Reifschneider and Williams, in the context of a model of the transmission mechanism like that analyzed here, though with a different assumption about the goals of stabilization policy.
} 
more.

It may be wondered why we discuss our proposal in terms of a (gap-adjusted) price-level target, rather than an inflation target. In fact, we could equivalently describe the policy in terms of a time-varying target for the gap-adjusted inflation rate $\tilde{\pi}_{t} \equiv \tilde{p}_{t}-\tilde{p}_{t-1}$. The reason that we prefer to describe the rule as a price-level targeting rule is that the essence of the rule is easily described in those terms. As we show below, a fixed target for the gap-adjusted price level would actually represent quite a good approximation to optimal policy, whereas a fixed inflation target would not come close, as it would fail to allow for any of the historydependence of policy that is necessary to mitigate the distortions resulting from the zero bound.

\subsection{A Simpler Proposal}

One may argue that an unappealing aspect of the rule suggested above is that it involves the term $\Delta_{t}$, which determines the change in the price-level target, and is only non-zero when the zero bound is binding. Suppose that the central bank's commitment to a policy rule can only become credible over time through repeated demonstrations of its commitment to act in accordance with it. In that case, the part of the rule that involves the adjustment of the target in response to target shortfalls when the zero bound binds might not come to be understood well by the private sector for a very long time, since the occasions on which the zero bound binds will presumably be relatively infrequent.

Fortunately, most of the benefits that can be achieved in principle through a credible commitment to the optimal targeting rule can be achieved through commitment to a much simpler rule, which would not involve any special provisos that are invoked only in the event of a liquidity trap. Let us consider the following simpler rule,

$$
p_{t}+\frac{\lambda}{\kappa} x_{t}=p^{*}
$$

where now the target for the gap-adjusted price level is fixed at all times. The advantage of this rule, although not fully optimal when the zero bound is binding, is that it may be more 
easily communicated to the public. Note that the simple rule is fully optimal in the absence of the zero bound. In fact, even if the zero bound occasionally binds, this rule results in distortions only a bit more severe than those associated with the fully optimal policy.

Figure 7 and 8 compares the result for these two rules. The dotted line shows the equilibrium under the constant price-level target rule in (3.13) whereas the solid line shows the fully optimal rule in (3.10)-(3.12). As the figures show, the constant price-level targeting rule results in state-contingent responses of output and inflation that are very close to those under the optimal commitment, even if under this rule the price level falls farther during the period while the zero bound binds, and only asymptotically returns from below to the level that it had prior to the disturbance. Table 1 shows that most of the welfare gain achieved by the optimal policy, relative to what can be achieved by a purely forward-looking policy such as a strict inflation target, is already achieved by the simple rule. The table reports the value of expected discounted losses (2.6), conditional on the occurrence of the disturbance in period zero, under the three policies shown in Figure 2, the optimal policy characterized in Figure 3, and under the constant price-level targeting rule. Both of the latter two historydependent policies are vastly superior to any of the strict inflation targets. While it is true that losses remain twice as large under the simple rule as under the optimal rule, we are referring to fairly small losses at this point.

As with the fully optimal rule, no estimate of the natural rate of interest is needed to implement the constant price-level targeting rule. At first, it may seem puzzling that a constant price-level targeting rule does well, since no account is taken of the size of the disturbance to the natural rate of interest. This is because a price-level target commits the central bank to undo any deflation by subsequent inflation; a larger disturbance, that creates a larger initial deflation, automatically creates greater inflation expectations in response. Thus there is an "automatic stabilizer" built into the price-level target, that is lacking under a strict inflation targeting regime. ${ }^{34}$

\footnotetext{
${ }^{34}$ Wolman (2003) also stresses this advantage of rules that incorporate a price-level target over rules that only respond to the inflation rate, such as a conventional Taylor rule.
} 
(a) inflation

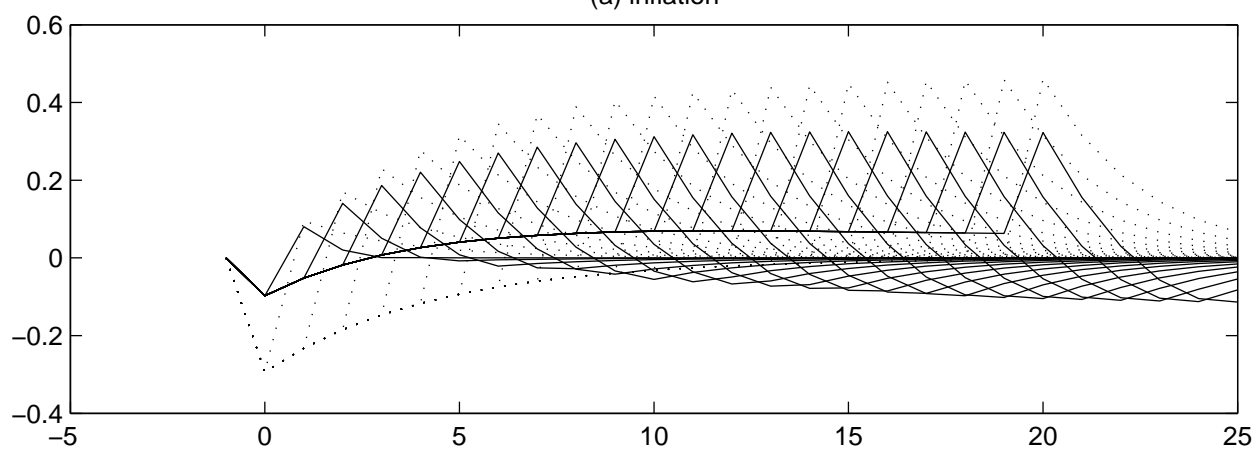

(b) output gap

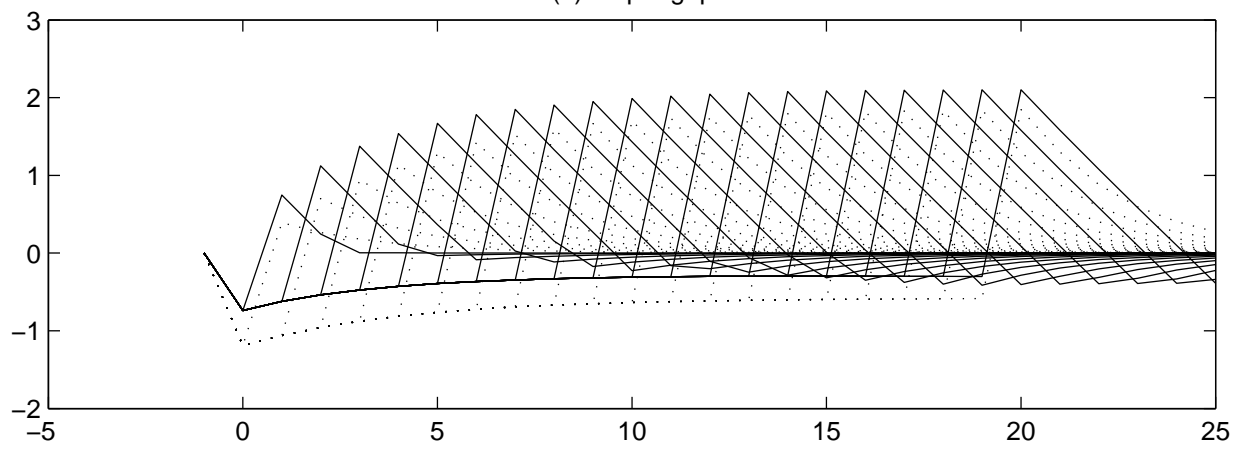

Figure 7: State-contingent paths of inflation and the output gap under the optimal targeting rule [solid lines] and under the simple rule [dotted lines].

A proper communication strategy for the central bank about its objectives and targets when outside the trap is of crucial importance for this policy rule to be successful. To see this, consider a rule that is equivalent to (3.13) when the zero bound is not binding. Taking the difference of (3.13) we obtain:

$$
\pi_{t}+\frac{\lambda}{\kappa}\left(x_{t}-x_{t-1}\right)=0
$$

Although this rule results in an identical equilibrium to the constant price-level targeting rule when the zero bound is not binding, the result is dramatically different when the zero bound is binding. This is because this rule implies that the inflation rate is proportional to the negative of the growth rate of the output gap. Thus it mandates deflation when there is growth in the output gap. This implies that the central bank will deflate once out of a liquidity trap since this is a period of output growth. This is exactly opposite to what is 
(a) nominal interest rate

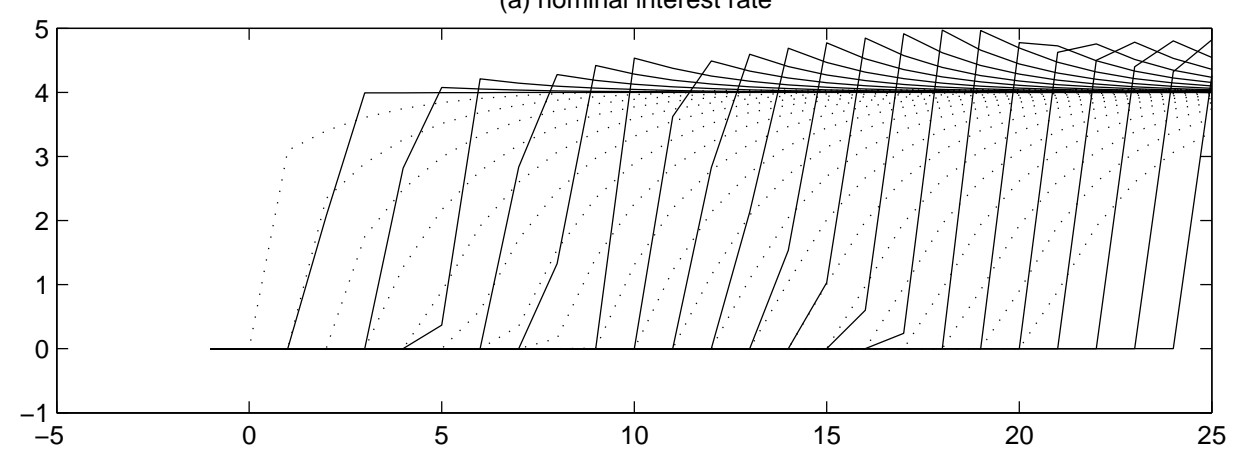

(b) price level

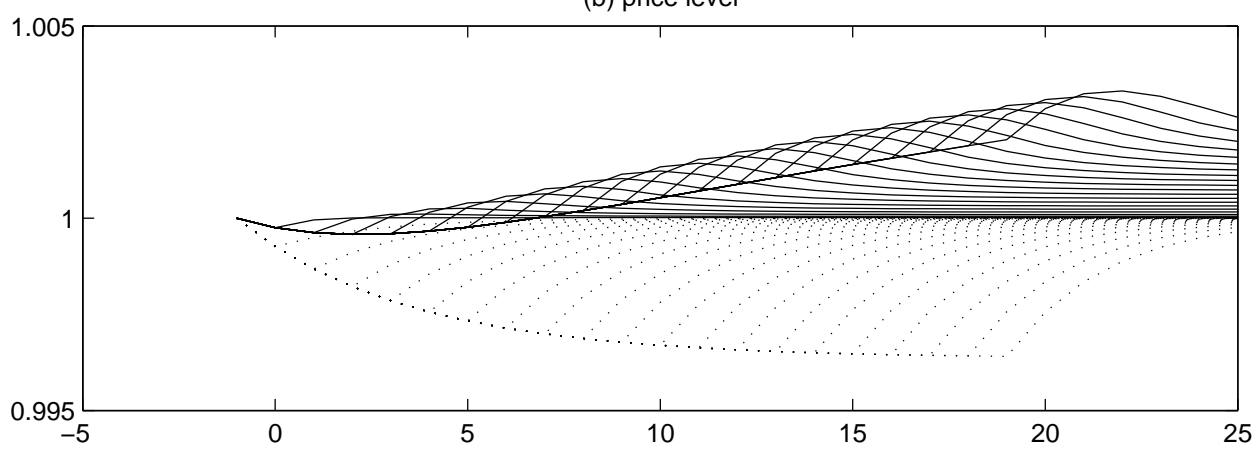

Figure 8: State-contingent paths of the nominal interest rate and the price level under the same two policies as in Figure 7.

optimal as we have observed above. Thus the outcome under this rule is even worse than a strict zero inflation target, even if this rule replicates the price level targeting rule when out of the trap. What this underlines is that it is not enough to replicate the equilibrium behavior that correspond to (3.13) at normal times to induce the correct set of expectations when the zero bound is binding. It is crucial to communicate to the public that the government is committed to a long-run price-level target. This commitment is exactly what creates the desired inflation expectations when the zero bound is binding.

\section{Preventing a Self-Fulfilling Deflationary Trap}

In our analysis thus far, we have assumed that the real disturbance results in a negative natural rate of interest only temporarily. We have therefore supposed that price-level stabilization will eventually be consistent with positive nominal interest rates, and accordingly 
Table 1: Relative losses under alternative policies [loss under zero inflation target $=100]$.

\begin{tabular}{|c|c|}
\hline \multicolumn{2}{|c|}{ Strict Inflation Targets } \\
\hline$\pi^{*}=0$ & 100 \\
\hline$\pi^{*}=1$ & 25.5 \\
\hline$\pi^{*}=2$ & 43.3 \\
\hline Price-Level Tar & $\overline{\text { Rules }}$ \\
\hline constant target & 0.098 \\
\hline optimal rule & 0.049 \\
\hline
\end{tabular}

that a time will foreseeably be reached at which it is possible for the central bank to create inflation by keeping short-term nominal rates at a low (but non-negative) level. Some may ask, however, if it is not possible for the zero bound to bind forever in equilibrium, not because of a permanently negative natural rate, but simply because deflation continues to be (correctly) expected indefinitely. If so, it might seem that the central bank's commitment to a non-decreasing price-level target would be irrelevant; the actual price level would fall further and further short of the target, but because of the binding zero bound, there would never be anything the central bank could do about this. Our proposed approach to the conduct of monetary policy might then be subject to a criticism similar to the one that Benhabib et al., (2001) levy against the "Taylor rule" (Taylor, 1993) as a guide to policy while it may be consistent with a desirable equilibrium, it cannot ensure that a bad outcome (perpetual deflation) will not occur instead.

In the model presented in section 2, a self-fulfilling permanent deflation is indeed consistent with both the Euler equation (1.2) for aggregate expenditure, the money-demand relation (1.3) and the pricing relations (1.7) - (1.9). Suppose that from some date $\tau$ onward, all disturbances $\xi_{t}=0$ with certainty, so that the natural rate of interest is expected to take the constant value $\bar{r}=\beta^{-1}-1>0$, as in the scenarios considered in section 3 . Then possible paths for inflation, output, and interest rates consistent with each of the relations just listed in all periods $t \geq \tau$ is given by

$$
i_{t}=0
$$




$$
\begin{gathered}
P_{t} / P_{t-1}=\beta<1 \\
p_{t}^{*} / P_{t}=\tilde{p}^{*} \equiv\left(\frac{1-\alpha \beta^{\theta-1}}{1-\alpha}\right)^{\frac{1}{1-\theta}}<1, \\
Y_{t}=\tilde{Y}
\end{gathered}
$$

for all $t \geq \tau$, where $\tilde{Y}<\bar{Y}$ is implicitly defined by the relation

$$
\Pi_{1}\left(\tilde{p}^{*}, \tilde{p}^{*}, 1 ; \tilde{Y}, \bar{m}(\tilde{Y} ; 0), 0\right)=0
$$

Note that this deflationary path is consistent with monetary policy as long as real balances satisfy $M_{t} / P_{t} \geq \bar{m}(\tilde{Y} ; 0)$ each period; faster growth of the money supply does nothing to prevent consistency of this path with the requirement that money supply equal money demand each period.

There remains, however, one further requirement for equilibrium in the model of section 2 , the transversality condition (1.6), or equivalently the requirement that households exhaust their intertemporal budget constraints. Whether the deflationary path is consistent with this condition as well depends, properly speaking, on the specification of fiscal policy: it is a matter of whether the government budget results in contraction of the nominal value of total government liabilities $D_{t}$ at a sufficient rate asymptotically. Under some assumptions about the character of fiscal policy, such as the "Ricardian" fiscal policy rule assumed by Benhabib et al., the nominal value of government liabilities will necessarily contract along with the price level, so that (1.6) is also satisfied, and the processes described above will indeed represent a rational-expectations equilibrium. In such a case, then, a commitment to the price-level targeting rule proposed in the previous section will be equally consistent with more than one equilibrium: if people expect the optimal price-level process characterized earlier, then that will indeed be an equilibrium, but if they expect perpetual deflation, this will be an equilibrium as well.

We can, however, exclude this outcome through a suitable commitment with regard to the asymptotic evolution of total government liabilities. Essentially, there needs to be a commitment to policies that ensure that the nominal value of government liabilities cannot 
contract at the rate required for satisfaction of the transversality condition despite perpetual deflation. One example of a commitment that would suffice is a commitment to a balancedbudget policy of the kind analyzed by Schmitt-Grohé and Uribe (2000). These authors show that self-fulfilling deflations are not possible under commitment to a Taylor rule, together with the balanced-budget fiscal commitment. The key to their result is that the fiscal rule includes a commitment not to allow budget surpluses any more than budget deficits would be allowed; hence it is not possible for the nominal value of government liabilities to contract, even when the price level falls exponentially forever.

The credibility of this sort of fiscal commitment might be doubted, and so it is worth mentioning that another way of maintaining a floor on the asymptotic nominal value of total government liabilities is through a commitment not to contract the monetary base, together with a commitment of the government to maintain a non-negative asymptotic present value of the public debt. In particular, suppose that the central bank commits itself to follow a base-supply rule of the form

$$
M_{t}=P_{t}^{*} \bar{m}\left(Y_{t} ; \xi_{t}\right)
$$

in each period when the zero bound binds (i.e., when it is not possible to hit the price-level target with a positive nominal interest rate), where

$$
P_{t}^{*} \equiv \exp \left\{p_{t}^{*}-\frac{\lambda}{\kappa} x_{t}\right\}
$$

is the current price-level target implied by the adjusted price-level target $p_{t}^{*}$. When the zero bound does not bind, the monetary base is whatever level is demanded at the nominal interest rate required to hit the price-level target. This is a rule in the same spirit as (1.11), specifying a particular level of excess supply of base money in the case that the zero bound binds, but letting the monetary base be endogenously determined by the central bank's other targets at all other times. Equation (4.1) is a more complicated formula than is necessary to make our point, but it has the advantage of making the monetary base a continuous function of other aggregate state variables at the point where the zero bound just ceases to bind.

This particular form of commitment has the advantage that it may be considered less 
problematic for the central bank to commit itself to maintain a particular nominal value for its liabilities than for the Treasury to do so. It can also be justified as a commitment that is entirely consistent with the central bank's commitment to the price-level targeting rule; even when the target cannot be hit, the central bank supplies the quantity of money that would be demanded if the price level were at the target level. Doing so - refusing to contract the monetary base even under circumstances of deflation - is a way of signalling to the public that the bank is serious about its intention to see the price level restored to the target level.

If we then assume a fiscal commitment that guarantees that

$$
\lim _{T \rightarrow \infty} E_{t} Q_{t, T} B_{T}=0,
$$

i.e., that the government will asymptotically be neither creditor nor debtor, the transversality condition (1.6) reduces to

$$
\lim _{T \rightarrow \infty} \beta^{T} E_{t}\left[u_{c}\left(Y_{T}, M_{T} / P_{T} ; \xi_{T}\right) M_{T} / P_{T}\right]=0 .
$$

In the case of the base-supply rule (4.1), this condition is violated in the candidate equilibrium described above, since the price-level and output paths specified would imply that

$$
\begin{aligned}
\beta^{T} E_{t}\left[u_{c}\left(Y_{T}, M_{T} / P_{T} ; \xi_{T}\right) M_{T} / P_{T}\right] & =\beta^{\tau} u_{c}(\tilde{Y}, \bar{m}(\tilde{Y} ; 0) ; 0) \bar{m}(\tilde{Y} ; 0) P_{T}^{*} / P_{\tau} \\
& \geq \beta^{\tau} u_{c}(\tilde{Y}, \bar{m}(\tilde{Y} ; 0) ; 0) \bar{m}(\tilde{Y} ; 0) P_{\tau}^{*} / P_{\tau}
\end{aligned}
$$

where the last inequality makes use of the fact that under the price-level targeting rule, $\left\{p_{t}^{*}\right\}$ is a non-decreasing series. Note that the final expression on the right-hand side is independent of $T$, for all dates $T \geq \tau$. Hence the series is bounded away from zero, and condition (4.3) is violated.

Thus a commitment of this kind can exclude the possibility of a self-fulfilling deflation of the sort described above as a possible rational-expectations equilibrium. It follows that there is a possible role for "quantitative easing" - understood to mean supply of base money beyond the minimum quantity required for consistency with the zero nominal interest rate - as an element of an optimal policy commitment. A commitment to supply base money 
in proportion to the target price level, and not the actual current price level, in a period in which the zero bound prevents the central bank from hitting its price-level target, can be desirable both as a way of ruling out self-fulfilling deflations and as a way of signalling the central bank's continuing commitment to the price-level target, even though it is temporarily unable to hit it.

Note that this result does not contradict the irrelevance proposition of section 2, for we have here made a different assumption about the nature of the fiscal commitment than the one made in section 2. Condition (4.2) implies that the evolution of total nominal government liabilities will not be independent of the central bank's target for the monetary base. As a consequence, the neutrality proposition of section 2 no longer holds. The import of that proposition is that expansion of the monetary base when the economy is in a liquidity trap is necessarily pointless; rather, it is that any effect of such action must depend either on changing expectations regarding future interest-rate policy or on changing expectations regarding the future evolution of total nominal government liabilities. The present discussion has illustrated circumstances under which expansion of the monetary base - or at any rate, a commitment not to contract it - could serve both of these ends.

Nonetheless, the present discussion does not support the view that the central bank should be able to hit its price-level target at all times, simply by flooding the economy with as much base money as is required to prevent the price level from falling below the target at any time. Our analysis in section 3 still describes all of the possible paths for the price level consistent with rational-expectations equilibrium, and we have seen that even if the central bank were able to choose the expectations that the private sector should have (as long as it were willing to act in accordance with them), the zero bound would prevent it from being able to fully stabilize inflation and the output gap. Furthermore, the degree of base expansion during a "liquidity trap" called for by rule (4.1) is quite modest. The monetary base will be gradually raised, if the zero bound continues to bind, as the price-level target is ratcheted up to steadily higher levels. But our calibrated example above indicates that this would typically involve only quite a modest increase in the monetary base, even in the 
case of a "liquidity trap" that lasts for several years. There would be no obvious benefit to the kind of rapid expansion of the monetary base actually tried in Japan over the past two years. An expansion of the monetary base of this kind is evidently not justified by any intentions regarding the future price level, and hence regarding the size of the monetary base once Japan exits from the "trap." But an injection of base money that is expected to be removed again once the zero bound ceases to bind should have little effect on spending or pricing behavior, as shown in section 2 .

\section{$5 \quad$ Further Aspects of the Management of Expectations}

In section 2, we argued that neither expansion of the monetary base as such nor purchases of particular types of assets through open-market purchases should have any effect on either inflation or real activity, except to the extent that such actions might result in changes in expectations regarding future interest-rate policy (or possibly expectations regarding the asymptotic behavior of total nominal government liabilities, and hence the question of whether the transversality condition should be satisfied). Because of this, we were able, in sections 3 and 4, to characterize the optimal policy commitment without any reference to the use of such instruments of policy; a consideration of the different possible joint paths of interest rates, inflation and output that would be consistent with rational-expectations equilibrium sufficed to allow us to determine the best possible equilibrium that one could hope to arrange, and to characterize it in terms of the interest-rate policy that one should wish for the private sector to expect.

However, this does not mean that other aspects of policy - beyond a mere announcement of the rule according to which the central bank wishes to be understood to be committed in setting future interest-rate policy - cannot matter. They may matter insofar as certain kinds of present actions may help to signal what the bank's intentions regarding future policy are, or may make it more credible that the central bank will indeed carry out these intentions. A full analysis of the ways in which policy actions may be justified as helping to steer expectations is beyond the scope of this article, and in any event the question is 
one that has as much to do with psychology and effective communication as with economic analysis. Nonetheless, we offer a few remarks here about the kinds of policies that might contribute to the creation of desirable expectations.

\subsection{Demonstrating Resolve}

One way in which current actions may help to create desirable expectations regarding future policy is by being seen to be consistent with the same principles that the central bank wishes the private sector to understand will guide its policy in the future. We have already mentioned one example of this, when we remarked that one way to convince the private sector that the central bank will follow the optimal price-level targeting rule following a period in which the zero bound has been hit is by following this rule before such a situation arises.

Our discussion in the previous section provides a further example. Adjustment of the supply of base money during the period in which the zero bound binds so as to keep the monetary base proportional to the target price level rather than the actual current price level can be helpful, even though it is irrelevant as far as interest-rate control is concerned, as a way of making visible to the private sector the central bank's belief about whether the price level ought properly to be (and hence, the quantity of base money that the economy ought to need). By making the existence of the price-level target more salient, such an action can help to create the expectations regarding future interest-rate policy that are necessary in order to mitigate the distortions created by the binding zero bound.

As a further example, Clouse at al. (2003) argue that open-market operations may be stimulative, even when the zero bound has been reached, because they "demonstrate resolve" to keep the nominal interest rate at zero for a longer time than would otherwise be expected. Here it should be remarked that an expansion of the monetary base when the zero bound is binding need not be interpreted in this way. Consider, for example, a central bank with a constant zero inflation target, as discussed in section 2.2. When the zero bound binds, such a bank is unable to hit its inflation target, and should exhibit frustration with this state of 
affairs. If some within the bank believe that it should always be possible to hit the target with sufficiently vigorous monetary expansion, one might well observe substantial growth in the monetary base at a time when the inflation target is being undershot. Nonetheless, this would not imply any commitment to looser policy subsequently; such a central bank would never intentionally allow the monetary base to be higher than that required to hit the inflation target, in a period in which it is possible to hit it. The result should be the equilibrium evolution shown in Figure 2, and no effect of the "quantitative easing" that occurs while the zero bound binds. This shows that it matters what the private sector understands to be the principle that motivates "quantitative easing", and not simply the size of the increase in the monetary base that occurs.

Similarly, open-market purchases of long-term Treasuries when short rates are at zero, as advocated by Bernanke (2002) and Cecchetti (2003), among others, may well have a stimulative effect even if portfolio-balance effects are quantitatively unimportant. We have argued in sections 2 and 3 that it is desirable for the central bank to commit itself under such circumstances to maintain low short-term rates even after the natural rate of interest rises again. The level of long rates can provide an indicator of the extent to which the markets actually believe in such a commitment. If a central bank's judgment is that long rates are remaining higher than they should be under the optimal equilibrium owing to privatesector skepticism about whether the history-dependent interest-rate policy will actually be followed, then a willingness to buy long bonds from the private sector at a price which it regards as more appropriate is one of way of demonstrating publicly that it expects to carry out its commitment regarding future interest-rate policy. Given that the private sector is likely to be uncertain about the nature of the central bank's commitment (in the case of imperfect credibility), and that it can reasonably assume that the central bank knows more about its own degree of resolve than others do, action by the central bank that is consistent with a belief on its own part that it will keep short rates low in the future is likely to shift private beliefs in the same direction. If so, open-market purchases of long bonds could lower long-term interest rates, stimulate the economy immediately, and bring the economy closer 
to the optimal rational-expectations equilibrium. Note, however, that the effect follows, not from the purchases themselves, but from the way in which they are interpreted. In order for them to be interpreted as indicating a particular kind of commitment with regard to future policy, it is important that the central bank have itself formulated such an intention, and that it speak about it to the public, so that its open-market purchases will be seen in this light.

Similar remarks apply to the proposals by McCallum (2000) and Svensson (2001) that purchases of foreign exchange be used to stimulate the economy through devaluation of the exchange rate. ${ }^{35}$ Under the optimal policy commitment described in section 2 , a decline in the natural rate of interest should be accompanied by depreciation of the exchange rate, both because nominal interest rates fall (and are expected to remain low for some time) and because the expected long-run price level (and hence the expected long-run nominal exchange rate) should increase. It follows that the extent to which the exchange rate depreciates can provide an indicator of the extent to which the markets believe that the central bank is committed to such the optimal policy; and if the depreciation is insufficient, purchases of foreign exchange by the central bank provide one way for it to demonstrate its own confidence in its policy intentions. Again, the effect in question is not a mechanical consequence of the bank's purchases, but instead depends on their interpretation. ${ }^{36}$ Furthermore, explaining the goals of the intervention in terms of bringing about an exchange rate consistent with a price-level target, rather than in terms of an exchange rate target that is presented as an end in itself, would allow a country to answer possible charges by its trading partners that it is seeking simply to "export deflation" to them. For while an exchange-rate depreciation can obviously not be achieved without another country's having to accept an exchange rate

\footnotetext{
${ }^{35}$ Svensson's proposal includes a target path for the price level, which the exchange-rate policy is used to (eventually) achieve, and in this respect is similar to the policy advocated here. The connection is made more explicit in Svensson (2003), where an announced path for the exchange rate is proposed as a way of creating the expectations regarding the future price level associated with the optimal equilibrium.

${ }^{36}$ The numerical analysis by Coenen and Wieland (2003) finds that an exchange-rate policy can be quite effective in creating stimulus when the zero bound is binding. But what is actually shown is that a rationalexpectations equilibrium exists in which the exchange rate depreciates and deflation is halted; these effects could be viewed as resulting from a credible commitment to a target path for the price level, similar to the one discussed in section 3 , and not requiring any intervention in the foreign exchange market at all.
} 
appreciation, achievement of a higher price-level target for one country in no way prevents other countries from raising their price levels as well.

\subsection{Providing Incentives to Improve Credibility}

A related but somewhat distinct argument is that actions at the zero bound may help to render the central bank's commitment to an optimal policy more credible, by providing the bank with a motive to behave in the future in the way that it would currently wish that people would expect it to behave. Here we briefly discuss how policy actions that are possible while the economy remains in a "liquidity trap" may be helpful in this regard. Our perspective is not so much that the central bank is in need of a "commitment technology" because it will itself be unable to resist the temptation to break its commitments later in the absence of such a constraint, as that it may well be in need of a way of making its commitment visible to the private sector. Taking actions now that imply that the central bank will be disadvantaged later if it were to deviate from the policy to which it wishes to commit itself can serve this purpose.

To consider what kind of current actions provide useful incentives, it is helpful to analyze (Markov) equilibrium under the assumption that policy is conducted by a discretionary optimizer, unable to commit its future actions at all, as in Eggertsson (2003a, b). Let us first consider what a Markov equilibrium under discretionary optimization would be like, in the case that the only policy instrument is the choice each period of a short-term nominal interest rate, and the objective of the central bank is the minimization of the loss function (2.6). As shown in section 3, if credible commitment of future interest-rate policy is possible, this problem has a solution in which the zero bound does not result in too serious a distortion, though it does bind.

Under discretion, however, the outcome will be much inferior. Note that discretionary policy (under the assumption of Markov equilibrium in the dynamic policy game) is an example of a purely forward-looking policy. It then follows from our argument in section 3 that the equilibrium outcome will correspond to the kind of equilibrium discussed there in 
the case of a strict inflation target. More specifically, it is obvious that the equilibrium is the same as under a strict inflation target $\pi^{*}=0$, since this is the inflation rate that will be chosen by the discretionary optimizer once the natural rate is again at its steady-state level. (From that point onward, a policy of zero inflation clearly minimizes the remaining terms in the discounted loss function.)

As shown in Figure 2, an expectation by the private sector that the central bank will behave in this fashion results in a deep and prolonged contraction of economic activity and a sustained deflation, in the case that the natural rate of interest remains negative for several quarters. We have also seen that these effects could largely be avoided, even in the absence of other policy instruments, if the central bank were able to credibly commmit itself to a history-dependent monetary policy in later periods. Thus, in the kind of situation considered here, there is a deflationary bias to discretionary monetary policy, although, at its root, the problem is again the one identified in the classic analysis of Kydland and Prescott (1977). Let us now consider instead the extent to which the outcome could be improved, even in a Markov equilibrium with discretionary optimization, by changing the nature of the policy game.

One example of a current policy action, available even when the zero bound binds, that can help to shift expectations regarding future policy in a desirable way is for the government to cut taxes and issue additional nominal debt, as discussed in Eggertsson (2003a). Alternatively, the tax cut can be financed by money creation - for when the zero bound binds, there is no difference between expanding the monetary base and issuing additional short-term Treasury debt at a zero interest rate. This is essentially the kind of policy imagined when people speak of a "helicopter drop" of additional money on the economy; but it is the fiscal consequence of such an action with which we are here concerned.

Of course, if the objective of the central bank in setting monetary policy remains as assumed above, this will make no difference to the discretionary equilibrium — the optimal policy once the natural rate of interest becomes positive again will once more appear to be the immediate pursuit of a strict zero inflation target. However, if the central bank also 
cares about reducing the social costs of increased taxation — whether due to collection costs or other distortions - as it ought if it really takes social welfare into account, the result is different. As shown in Eggertsson (2003a), the tax cut will then increase inflation expectations, even if the government cannot commit to future policy. ${ }^{37}$

Another instrument that may be used to change expectations regarding future monetary policy is open-market purchases of real assets or foreign exchange. An open-market purchase of real assets (say, real estate) can be thought of as another way of increasing nominal government liabilities, which should affect inflation incentives in much the same way as deficit spending, as discussed in Eggertsson (2003a). The alternative approach has the advantage of not worsening the overall fiscal position of the government - a current concern in Japan, owing to the size of the existing gross debt — while still increasing the fiscal incentive for inflation. A further advantage of this approach is that it need not depend on a perceived central-bank interest in reducing the burden of the public debt. Since the (nominal) capital gains from inflation accrue to the central bank itself under this policy, the central bank may be perceived to have an incentive to inflate simply on the ground that it cares about its own balance sheet, for example on the ground that a strong balance sheet will help to ensure its independence. (One can easily argue that under a rational scheme of cooperation between the central bank and the government, the central bank should not choose policy on the basis of concerns about its balance sheet — but under such an ideal regime, it should choose monetary policy with a view to reduction of the burden of the public debt, among other goals.)

The incentive effects of open-market operations in foreign exchange are even simpler, as shown by Eggertsson (2003b). Open-market purchases of foreign assets give the central bank an incentive to inflate in the future in order to obtain capital gains at the expense of foreigners. These will be valuable if it cares either about its own balance sheet or about reducing the burden of the public debt, as in the case of real asset purchases. However,

\footnotetext{
${ }^{37}$ In the next section, we consider why this mechanism has not resulted in greater inflationary expectations in Japan, given the current size of the public debt.
} 
capital gains on foreign exchange as a result of depreciation of the domestic currency will be valuable even in the case that the central bank does not care about its balance sheet (for example, because it cooperates perfectly with the Treasury) and yet does not care about the burden of the debt either (for example, because non-distorting sources of revenue are available to the Treasury). For capital gains at the expense of foreigners would allow an increase in domestic spending (by either the government or the private sector), and this must be valued by a central bank that acts in the national interest.

Under rational expectations, of course, no such capital gains are realized on average. Still, the purchase of foreign assets can work as a commitment device, because reneging on its inflation commitment would cause capital losses if the government holds foreign assets. Purchases of foreign assets are thus a way of committing the government to looser monetary policy in the future. This creates a reason for purchases of foreign exchange to cause a devaluation (which will also stimulate current demand), even without any assumption of a deviation from interest-rate parity, of the kind relied upon by authors such as McCallum (2000) in recommending devaluation for Japan.

Clouse et al. (2003) argue that open-market purchases of long-term Treasuries should also change expectations in a way that results in immediate stimulus. The argument is that if the central bank were not to follow through on its commitment to keep short rates low for a period of time, it should suffer a capital loss on the long bonds that it purchased at a price that made sense only on the assumption that it would keep interest rates low. Similarly, Tinsley (1999) has proposed for a policy that would create this kind of incentive even more directly, namely, the sale by the Fed of options to obtain federal funds at a future date at a certain price, on which the Fed would then stand to lose money if it did not keep the funds rate at the rate to which it had previously committed itself.

While these proposals should also help to reinforce the credibility of the kind of policy commitment associated with the optimal equilibrium (characterized in section 2), they have at least one important disadvantage relative to purchases of real assets or of foreign exchange. This is that they only provide the central bank an incentive to maintain low nominal interest 
rates for a certain period of time; they do not provide it with an incentive to ensure that the price level eventually rises to a higher level, and so they may do little to counter privatesector expectations that nominal interest rates will remain low for years - but because goods prices are going to continue to fall, not because the central bank is committed to eventual reflation. This is arguably the kind of expectations that have now taken root in Japan, where even ten-year bond yields are already well below one percent, though prices continue to fall and economic activity remains anemic. Creation of a perception that the central bank has an incentive to continue trying to raise the price level, and not to be content as long as nominal interest rates remain low, may be more a successful way of creating the sort of expectations associated with the optimal equilibrium.

\section{Reflections on Policy Options for Japan}

Some remarks may be in order about the implications of our analysis for the continuing efforts to halt deflation in Japan. First of all, the irrelevance proposition presented in section 1 indicates that "quantitative easing" beyond the size of monetary base required in order to keep the call rate essentially at zero need not have any effect at all on either real activity or the path of prices. We suspect that this explains the apparent ineffectiveness of "quantitative easing" as practiced by the Bank of Japan since March 2001.

Of course, in our analysis, open-market operations that increase the monetary base (when short-term nominal interest rates are already at zero) are only ineffective insofar as they do not change expectations about the future conduct of monetary policy. The massive increases in base money implemented over the past two years have not halted deflation, on this account, because, unlike the open-market operations hypothesized by Auerbach and Obstfeld (2003), they were not understood to imply a corresponding permanent increase in the monetary base. It seems to us quite plausible that these increases in base money have not been expected

to be permanent. Not only has the BOJ made no reference to any intention to target a higher price level (or a depreciated value of the yen on the foreign exchange markets) in the future, but the very size of the increases in base money that have occurred are such 
as to make it implausible that they are intended to be permanent. After all, that would imply that, once it has become possible to abandon the zero-interest-rate policy (so that excess reserves will no longer be held, beyond those that generate services of sufficient value to justify the foregone interest), the general level of prices would probably have to rise by nearly 50 percent — something that one could not imagine being accepted even by a central bank firmly committed to Krugmanesque "irresponsibility".

An alternative view, argued by Hetzel (2003), is that the BOJ has not actually increased bank reserves by more than the increase that has occurred in desired reserves at a zero overnight interest rate, and that it is only for this reason that no further stimulus to aggregate demand has been observed. This seems implausible to us, as it would require that a dramatic increase in the demand for bank reserves occurred at precisely the time that the BOJ initiated the policy of "quantitative easing." However, even if Hetzel's interpretation of BOJ policy is correct, "demand-determined reserves provision" would imply that the increases in base money since March 2001 are not intended to be permanent; for they should be reversed as soon as a decline in perceived risks to the banking sector allows the ratio of desired reserves to the volume of transactions to return to a more normal level. In our view, it is the BOJ's failure to contradict such expectations regarding its future policy that has undermined the policy of "quantitative easing". It is these expectations regarding future policy that need directly to be addressed, rather than further swelling the current supply of bank reserves, in a way that would make it even less plausible to imagine that the increase is intended to be permanent. $^{38}$

Our model can also shed light on the failure of deficit spending to do more to stimulate the Japanese economy and eliminate expectations of deflation. In our model - a representative-

\footnotetext{
${ }^{38}$ We have argued in section 4 that it can be desirable to supply a quantity of base money greater than is required to keep interest rates at zero, under a policy commitment that serves to exclude the possibility of a self-fulfilling deflationary trap, even after the natural rate of interest has become positive. However, under the rule recommended there, the base money supply while the zero bound binds should be one that would not be withdrawn were the bound to cease to bind: it is the monetary base that one expects would be demanded if the target (gap-adjusted) price level were to be achieved, and so (except for the small adjustments in the price-level target that one expects to occur) it corresponds to the monetary base that one expects to supply in the future, once the target can be hit.
} 
household model with no constraints on borrowing against future income, in which we also abstract from the supply-side effects of taxation - the principle of "Ricardian equivalence" holds. The aspects of the model just mentioned are plainly idealizations, and one would not expect Ricardian equivalence to hold exactly in a more realistic model. Nonetheless, the essential prediction of such a model does not seem to have been far off in Japan: decreases in government saving (increases in government borrowing) have resulted in offsetting increases in private saving, so that little stimulus to aggregate demand has been achieved.

In our model, government deficits could stimulate aggregate demand, and head off deflation, if they changed expectations regarding future monetary policy. One reason why deficits might lead to an expectation of a higher future price level is provided in the analysis of Eggertsson (2003a). If future monetary policy is expected to be conducted under discretion (and hence to be purely forward-looking), but to take account of the distortions resulting from high tax rates, and not solely of inflation and output stabilization objectives, then a higher nominal public debt should result in more inflationary monetary policy; and so current deficits, that increase the anticipated future level of nominal public debt, should foreseeably increase the incentives for inflation in the future, as discussed in section 5 .

The anticipation of such an effect, however, depends on particular beliefs about the way in which monetary policy is likely to be conducted in the future. The model of central-bank behavior just sketched probably does not match the expectations of many observers regarding the likely behavior of the Bank of Japan. In particular, the public may not anticipate that the BOJ will care much about reducing the burden of the public debt when determining future monetary policy. The expressed resistance of the Bank to suggestions that it increase its purchases of Japanese government bonds, on the ground that this could encourage a lack of fiscal discipline, ${ }^{39}$ has certainly suggested that reducing the burden of government finance is not among its highest priorities. As Eggertsson (2003a) stresses, in order for fiscal policy to be effective as a means of increasing inflationary expectations, fiscal and monetary policy must be coordinated to maximize social welfare. ${ }^{40}$ The consequences of a narrow concern

\footnotetext{
${ }^{39}$ See, e.g., Asahi Shimbun (1999).
} 


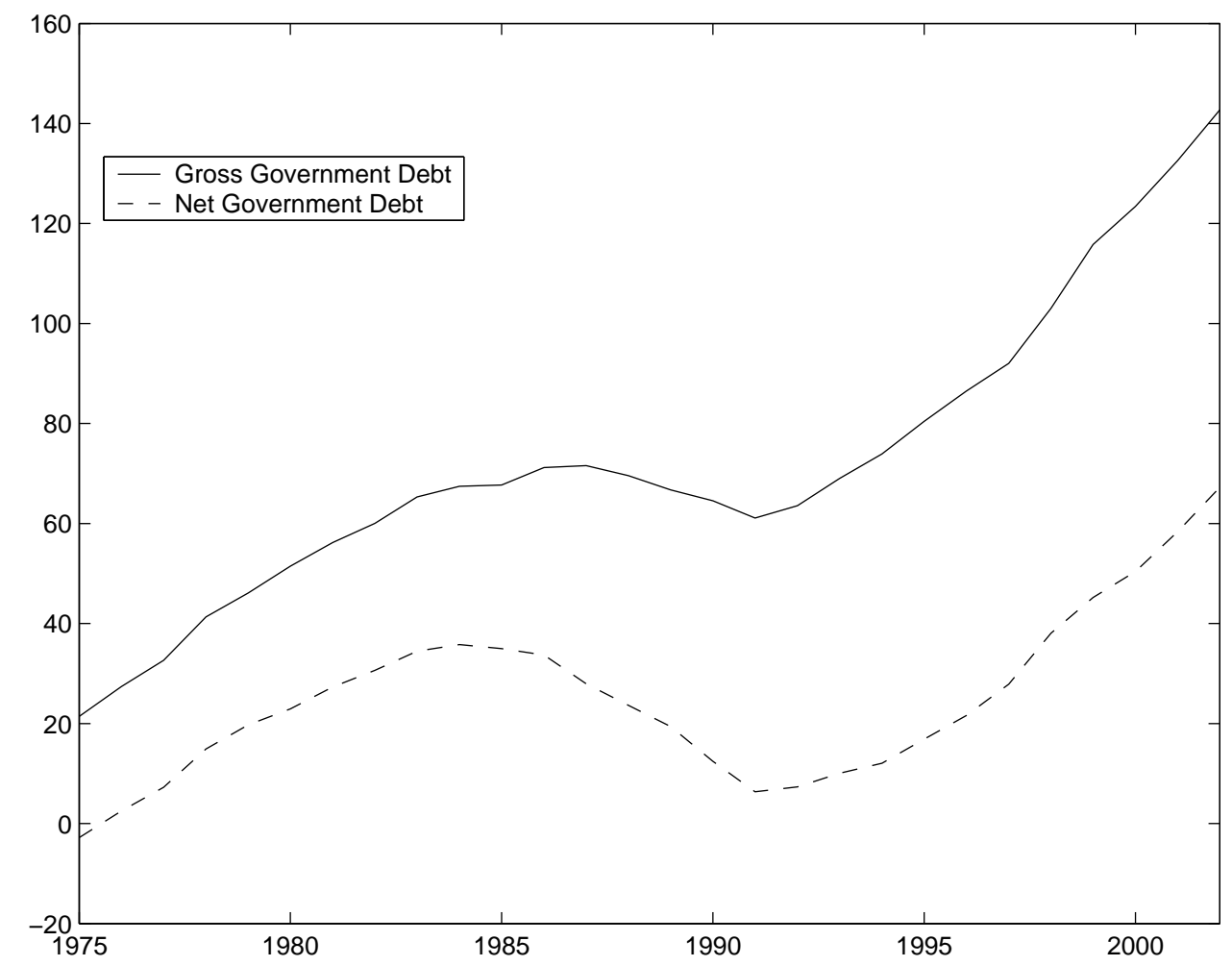

Figure 9: Ratio of net and gross Japanese government debt to GDP..

with inflation stabilization on the part of the central bank, together with an inability to credibly commit future monetary policy, can be dire, even from the point of view of the bank's own stabilization objectives, as we have shown in section 2 .

Indeed, we would not propose that larger deficits are what Japan needs at this point in order to raise inflationary expectations. The Japanese public debt has doubled over the past decade, as shown in Figure 9; we feel that the size of the nominal public debt that has already been accumulated ought to provide a substantial incentive for an increase in the general level of prices, if the BOJ takes into account the desirability of reducing the burden of the public debt. It is true that the figures often cited as evidence of the fiscal recklessness of the Japanese government somewhat overstate the true inflation incentives provided by the public debt. For although gross nominal debt is 140 percent of annual GDP in Japan today, a substantial portion of Treasury debt is held by other governmental institutions.

\footnotetext{
${ }^{40}$ Bernanke (2003) argues along similar lines.
} 


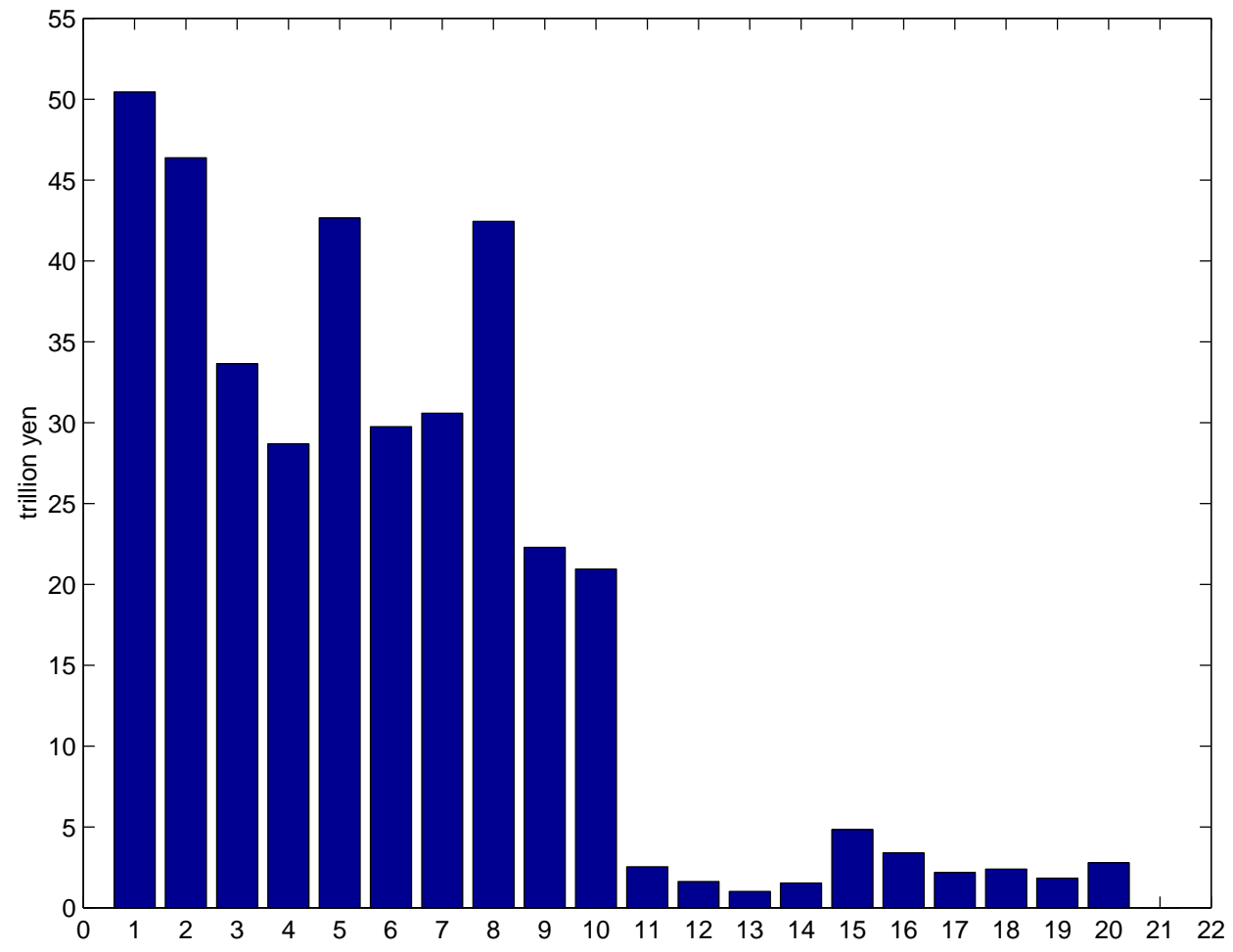

Figure 10: Maturity structure of outstanding Japanese government debt in years.

Government institutions such as Social Security, Postal Savings, Postal Life Insurance and the Trust Fund Bureau hold a large part of this nominal debt. If the part of the public debt that is held by these institutions is subtracted from the total value of gross government debt it turns out that the "net" government debt is only 67 percent of GDP. It is important to note that most of the government institutions that hold the government nominal debt have real liabilities. For example, Social Security (that holds roughly $25 \%$ of the nominal debt held by the government itself) pays Japanese pensions and medical expenses. Those pensions are indexed to the CPI. If inflation increases, the real value of Social Security assets will decrease but the real value of most its liabilities remain unchanged. Thus the Ministry of Finance would eventually have to step in to make up for any loss in the value of Social Security assets if the government is to keep its pension program unchanged. Therefore, the gains of reducing the real value of outstanding debt is partly offset by a decrease in the real value of the assets of government institutions such as Social Security. 


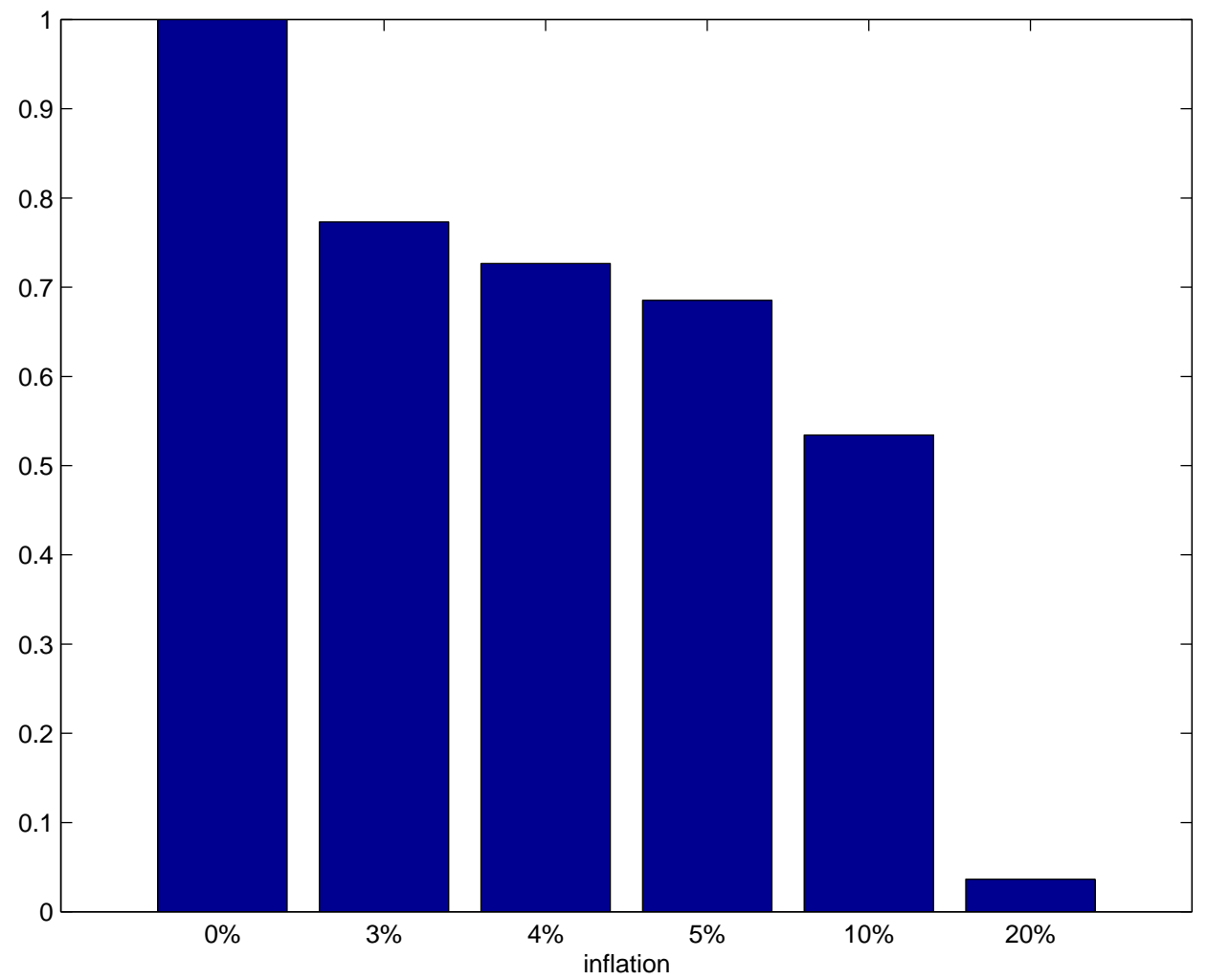

Figure 11: Reduction in the real value of public debt if rolled over to 2021.

Even so, Japanese government debt is large enough that a substantial reduction in the revenues that will have to be raised through taxation could be achieved by even moderate inflation. Figure 10 shows the maturity structure of outstanding debt in Japan, i.e., it shows the nominal value of debt due to be paid from 2003-2023. We can use these data to calculate the government's revenue gains from inflation, if we make some simple assumption about the evolution of the natural rate of interest. Figure 11 shows how much the real debt burden would be reduced under different inflation rates. The underlying assumption is that the natural real rate is negative for 5 years at $-2 \%$ and then returns to a positive rate. The figure shows the real value of the debt in 2023 if it is rolled over from 2003 onwards. We express the value of the debt as a ratio of real debt for a given inflation target over the real value of the debt if there would be zero inflation. We display this ratio for 3, 4, 5, 10 and 20 percent inflation. We observe that there would be a substantial reduction in the real value 
of the debt with even a fairly modest rate of inflation; for example, it is reduced by more than a quarter by a 4 percent inflation. Thus the level of public debt that already exists would seem to provide a non-trivial incentive for inflation.

In our view, what is needed is not more debt, but rather a clarification of the principles that will guide future monetary policy, of a kind that would imply that the existing incentives for inflation will actually be reflected in future monetary policy. (In the analysis of Eggertsson, 2003a, an increase in the deficit is needed to reduce the current rate of deflation; but this is under the assumption that the rate of expected future inflation given the already existing nominal public debt reflects the incentives to inflate provided by that level of debt.) Thus, once again, the key to the ineffectiveness of the measures undertaken thus far is the lack of any reason for the public to believe that either the recent growth in the monetary base or the recent explosion of the public debt implies a likelihood of looser monetary policy in the future.

Indeed, our most important general conclusion is that the key to dealing with a situation in which monetary policy is constrained by the zero lower bound on short-term nominal interest rates is the skillful management of expectations regarding the future conduct of policy. By "management of expectations" we do not mean that the central bank should imagine that with sufficient guile it can lead the private sector to believe whatever if wishes it to, independently of what it actually does; we have instead assumed that there is no point in trying to get the private sector to expect something that it does not itself intend to bring about. But we do contend that it is highly desirable for a central bank to be able to commit itself in advantage to a course of action that is desirable due to the benefits that flow from its being anticipated, and then to work to make this commitment credible to the private sector.

We have further argued that a particularly desirable form of commitment regarding future monetary policy would be a commitment to eventually achieve a general level prices as high as prices would have been in the absence of a period in which the zero bound constrained policy — or ideally, even to a slightly higher level, as a consequence of the binding zero 
bound. This is not precisely the same advice as the often-heard prescription that Japan needs an "inflation target". Indeed, our analysis in section 2 has shown that the purely forward-looking pursuit of a fixed inflation target can have quite bad consequences - either a sharp contraction during the period of the liquidity trap, if the inflation target is set at a desirable long-run level, or persistent distortions as a result of long-run inflation, if the inflation target is set at a high enough level to keep the zero bound from binding even while the natural rate of interest is negative. A target for the price level instead makes the policy commitment history-dependent in a desirable way: the farther prices fall below their target level as a result of persistence of the liquidity trap, the greater the length of time that people have reason to expect policy to continue to be loose, after the date at which the natural rate of interest has again become positive.

The Bank of Japan has resisted calls for adoption of an inflation target, on the ground that while the zero bound is binding, it lacks an instrument with which to hit such a target. For example, Kunio Okina has argued that "because short-term interest rates are already at zero, setting an inflation target of, say, 2 percent wouldn't carry much credibility" (Dow Jones News, 1999). However, in our view, the announcement of a price-level target can be valuable, even when it is not considered likely that the target can be hit within, say, the coming year. Under the optimal targeting rule derived for our model, the central bank's commitment is only to adjust short-term nominal interest rates so as to hit the target if this does not require an interest rate lower than zero, and otherwise to maintain a zero interest rate until the target can be his. Thus consistent undershooting of the target for a year or longer would not undermine the credibility of the central bank's announced target, as long as the zero-interest-rate policy had been consistently been maintained during such a period. Nor would the announcement of the target have been pointless in the period in which it could not be hit. For awareness of the level which prices must reach before the ZIRP can be abandoned automatically creates expectations of more inflation in the future (and of a longer period of low interest rates), the lower present prices may fall; and expectations of this kind should reduce the extent to which prices can actually fall, even during the period 
in which the zero bound continues to bind.

One policy that may have had some success in Japan is the policy of repeated interventions in the foreign exchange market by the Ministry of Finance during the first half of 2003. This policy appears to have prevented further appreciation of the yen, in which case it may well have played an important role in the recent improvement in real growth in Japan. As discussed in the previous section, foreign-exchange market intervention is another example of a policy that should have negligible effects on either asset prices or the economy more generally, except insofar as it is taken to signal a chance in the likely stance of future monetary policy. Yet intervention against an exchange rate that indicates market expectations inconsistent with the policy commitments of the government may succeed in changing those expectations, as argued by Svensson (2003).

Even so, we would expect such an effect to be achieved more reliably if the foreignexchange purchases were accompanied by explicit discussion of the policy targets that imply misalignment of the current exchange rate. We believe, furthermore, that it would be best to explain such interventions in terms of a target for the general level of prices in Japan, rather than a target (or target path) for the exchange rate itself. One advantage of this is that Japan's trading partners — who may themselves be concerned about the risk of deflation, as in the U.S. this year - would then have no reason to interpret the MOF's actions as part of a strategy intended to "export deflation" abroad. Of course, in order for the public to believe that future Japanese policy will seek to achieve a particular price-level target, they would above all have to believe in the commitment of the BOJ to the target. Thus, once again, it would seem highly desirable for the BOJ and MOF to be able to coordinate both their policy actions and the way in which they speak about the targets that will guide future policy.

Given the role of private-sector anticipation of history-dependent policy in making possible a desirable outcome when an economy finds itself in a liquidity trap, it is important for the authorities to develop effective methods of signaling their policy commitments to the private sector. An essential precondition for this, certainly, is for the central bank itself to 
clearly understand the kind of history-dependent behavior to which it should be seen to be committed, so that it can communicate its thinking on the matter and act consistently with the principles that it wishes the private sector to understand, and that it wishes for other branches of the government to support. Simply conducting policy in accordance with a rule may not suffice in itself to bring about an optimal, or nearly optimal, equilibrium; but it is the place to start. 


\section{References}

Adam, Klaus, and Roberto M. Billi, "Optimal Monetary Policy under Commitment with a Zero Bound on Nominal Interest Rates," unpublished, University of Frankfurt, August 2003.

Asahi Shimbun, "Bank of Japan Advised to 'Print Money' to Escape Deflation," Dow Jones News, February 10, 1999.

Auerbach, Alan J., and Maurice Obstfeld (2003), "The Case for Open-Market Purchases in a Liquidity Trap," working paper, University of California, Berkeley.

Agell, Jonas, and Mats Persson, "Does Debt Management Matter?" in J. Agell, M. Persson, and B.M. Friedman, Does Debt Management Matter? Oxford: Claredon Press, 1992.

Benhabib, Jess, Stephanie Schmitt-Grohé, and Martin Uribe, "The Perils of Taylor Rules," Journal of Economic Theory 96: 40-69 (2001).

Bernanke, Ben S., "Deflation: Making Sure 'It' Doesn't Happen Here," remarks before the National Economists' Club, Washington, D.C., November 21, 2002.

_- - - "Some Thoughts on Monetary Policy in Japan," address to the Japan Society of Monetary Economics, Tokyo, May 31, 2003.

Brock, William A., "Money and Growth: The Case of Long-Run Perfect Foresight," International Economic Review 15: 750-777 (1974).

_- - (1975), "A Simple Perfect Foresight Monetary Rule," Journal of Monetary Economics 1: 133-150.

Buiter, Willem H., and Nikolaos Panigirtzoglou, "Liquidity Traps: How to Avoid Them and How to Escape Them," in Wim F.V. Vanthoor and Joke Mooi, Reflections on Economics and Econometrics: Essays in Honour of Martin M.G. Fase, De Nederlandsche Bank, 2001.

Calvo, Guillermo A. (1983), "Staggered Prices in a Utility-Maximizing Framework," Journal of Monetary Economics, 12: 383-98.

Cecchetti, Stephen G. (2003), "Central Banks have Plenty of Ammunition," Financial Times, March 17, p. 13.

Clarida, Richard, Jordi Gali and Mark Gertler (1999), "The Science of Monetary Policy: A New Keynesian Perspective," Journal of Economic Literature 37: 1661-1707. 
Clouse, James, Dale Henderson, Athanasios Orphanides, David Small, and Peter Tinsley, "Monetary Policy when the Nominal Short-Term Interest Rate is Zero," Federal Reserve Board, July 2003. (Forthcoming, Topics in Macroeconomics.)

Coenen, Gunter and Volker Wieland, "The Zero-Interest-Rate Bound and the Role of the Exchange Rate for Monetary Policy in Japan," Carnegie-Rochester Conference Series on Public Policy, forthcoming 2003.

Dow Jones News, "Japan BOJ Official: Hard to Set Inflation Targets," August 11, 1999.

Eggertsson, Gauti (2003a), "Fighting Deflation at Zero Nominal Interest Rates: Committing to Being Irresponsible," IMF Working Paper, forthcoming.

_ _ - (2003b), "Foreign Exchange as a Commitment Device," IMF, in progress.

- - - and Michael Woodford, "The Zero Bound on Interest Rates and Optimal Monetary Policy," Brookings Papers on Economic Activity xxxxx (2003).

Feldstein, Martin, "Commentary: Is There a Role for Discretionary Fiscal Policy?" in Rethinking Stabilization Policy, Kansas City: Federal Reserve Bank of Kansas City, 2002.

Fischer, Stanley, "Why are Central Banks Pursuing Long-Run Price Stability?" in Achieving Price Stability, Kansas City: Federal Reserve Bank of Kansas City, 1996.

Frankel, Jeffrey, "Portfolio Crowding-Out Empirically Estimated," Quarterly Journal of Economics 100: 1041-1066 (1985).

Friedman, Benjamin M., "Debt Management Policy, Interest Rates and Economic Activity," in J. Agell, M. Persson, and B.M. Friedman, Does Debt Management Matter? Oxford: Claredon Press, 1992.

Gesell, Silvio, The Natural Economic Order [1929]. English translation by Philip Pye, San Antonio: Free-economy Publishing Co., 1934.

Giannoni, Marc P., and Michael Woodford, "Optimal Interest-Rate Rules: I. General Theory," NBER working paper no. 9419, December 2002.

_- _ - and _ _ _ , "Optimal Inflation Targeting Rules," in B.S. Bernanke and M. Woodford, eds., Inflation Targeting, Chicago: University of Chicago Press, forthcoming 2003.

Goodfriend, Marvin, "Overcoming the Zero Bound on Interest Rate Policy," Journal of Money, Credit and Banking 32(2): 1007-1035 (2000). 
Hess, Gregory D., "The Maturity Structure of Government Debt and Asset Substitutability in the United Kingdom," in K.A. Chrystal, ed., Government Debt Structure and Monetary Conditions, London: Bank of England, 1999.

Hetzel, Robert L., "Japanese Monetary Policy and Deflation," Federal Reserve Bank of Richmond Economic Quarterly, 89(3): 21-52 (2003).

Iwamura, Mitsuru, and Tsutomu Watanabe, "Price Level Dynamics in a Liquidity Trap," unpublished, Waseda University, December 2002.

Jung, Taehun, Yuki Teranishi, and Tsutomu Watanabe, "Zero Bound on Nominal Interest Rates and Optimal Monetary Policy," Discussion Paper no. 525, Kyoto Institute of Economic Research, 2001.

Keynes, John Maynard (1936), The General Theory of Employment Interest and Money, London: Macmillan.

Kimura, Takeshi, Hiroshi Kobayashi, Jun Muranaga, and Hiroshi Ugai, "The Effect of 'Quantitative Monetary Easing' at Zero Interest Rates," unpublished, Bank of Japan, September 2002.

Krugman, Paul (1998), "It's Baaack! Japan's Slump and the return of the Liquidity Trap," Brookings Papers on Economic Activity 1998:2, pp. 137-187.

Kydland, Finn E., and Edward C. Prescott, "Rules Rather than Discretion: The Inconsistency of Optimal Plans," Journal of Political Economy 85: 473-491 (1977).

Lucas, Robert E., Jr., and Nancy L. Stokey (1987), "Money and Interest in a Cash-inAdvance Economy," Econometrica 55(3), May 1987, pages 491-513.

McCallum, Bennett (2000), "Theoretical Analysis Regarding a Zero Lower Bound on Nominal Interest Rates," Journal of Money, Credit and Banking 32(2): 870-904.

Meltzer, Allan, "A Reality Check for the Conventional Wisdom," Financial Times, August 18, 2003.

Meulendyke, Ann-Marie, U.S. Monetary Policy and Financial Markets, New York: Federal Reserve Bank of New York, 1998.

Modigliani, Franco, and Richard Sutch (1966), "Innovations in Interest Rate Policy," American Economic Review 56: 178-97.

Okun, Arthur M. (1963), "Monetary Policy, Debt Management and Interest Rates: A Quantitative Assessment," in Commission on Money and Credit, Stabilization Poli- 
cies, Englewood Cliffs: Prentice-Hall.

Orphanides, Athanasios, "Monetary Policy in Deflation: The Liquidity Trap in History and Practice," unpublished, Federal Reserve Board, April 2003.

Phelps, Edmund S., Inflation Policy and Unemployment Theory, London: MacMillan, 1972.

Reifschneider, David, and John C. Williams, "Three Lessons for Monetary Policy in a Low Inflation Era," Journal of Money, Credit and Banking 32: 936-966 (2000).

Roley, C. Vance, "The Effect of Federal Debt-Management on Corporate Bond and Equity Yields," Quarterly Journal of Economics 97: 645-68 (1982).

Sargent, Thomas J., and Neil Wallace, "Some Unpleasant Monetarist Arithmetic," Federal Reserve Bank of Minneapolis Quarterly Review, 5(3): 1-17 (1981).

Schmitt-Grohé, Stephanie and Martin Uribe (2000), "Price Level Determinacy and Monetary Policy under a Balanced-Budget Requirement," Journal of Monetary Economics, 45, 211-246.

Sidrauski, Miguel (1967), "Rational Choice and Patterns of Growth in a Monetary Economy," American Economic Review 57(2): 534-544.

Sugo, Tomohiro, and Yuki Teranishi, "Optimal Monetary Policy Rule under the NonNegative Constraint on Nominal Interest Rates," unpublished, Bank of Japan, July 2003.

Summers, Lawrence (1991), "Panel Discussion: Price Stability. how Should Long-Term Monetary Policy Be Determined?" Journal of Money, Credit and Banking 23: 625-631.

Svensson, Lars E.O. (2001), "The Zero Bound in an Open Economy: A Foolproof Way of Escaping from a Liquidity Trap," Bank of Japan Monetary and Economic Studies 19(S-1), 277-312.

- - (2003), "Escaping from a Liquidity Trap and Deflation: The Foolproof Way and Others," Journal of Economic Perspectives, forthcoming.

Taylor, John B. (1993), "Discretion versus Policy Rules in Practice," Carnegie-Rochester Conference Series on Public Policy 39: 195-214.

Tinsley, Peter A., "Short Rate Expectations, Term Premiums, and Central Bank Use of Derivatives to Reduce Policy Uncertainty," Financial and Economics Discussion 
Series no. 1999-14, February 1999.

Uhlig, Harald, "Should We Be Afraid of Friedman's Rule?" Journal of the Japanese and International Economies 14: 261-303 (2000).

Wallace, Myles S., and John T. Warner (1996), "Do Excess Holding-Period Returns Depend on the Composition of Outstanding Federal Debt?" Journal of Money, Credit and Banking 28: 132-139.

Wallace, Neil, "A Modigliani-Miller Theorem for Open-Market Operations," American Economic Review 71: 267-274 (1981).

Wolman, Alexander L., "Real Implications of the Zero Bound on Nominal Interest Rates," Journal of Money, Credit and Banking, forthcoming 2003.

Woodford, Michael, "Optimal Monetary Policy Inertia," NBER Working Paper no. 7261, August 1999.

_- - , "Pitfalls of Forward-Looking Monetary Policy," American Economic Review 90(2): 100-104 (2000).

- - - Interest and Prices: Foundations of a Theory of Monetary Policy, Princeton: Princeton University Press, forthcoming 2003. 